\title{
UNA SEPULTURA CON ARMAS DE BAJA ÉPOCA IBÉRICA (O ÉPOCA ROMANA REPUBLICANA) EN LA NECRÓPOLIS DEL «CERRO DE LAS BALAS» (ÉCIJA, SEVILLA)*
}

\author{
POR \\ ESTHER NÚÑEZ PARIENTE DE LEÓN y FERNANDO QUESADA SANZ
}

\section{RESUMEN - ABSTRACT}

Las armas de época ibérica son rarísimas en Andalucía Occidental, en buena parte debido a la práctica ausencia de necrópolis, que es donde las armas se han documentado en mayor número durante toda la Edad del Hierro peninsular. Se presenta en este trabajo una de las pocas excepciones a esta regla: una sepultura 'de guerrero' hallada en la necrópolis del 'Cerro de las Balas' (así llamado por los numerosos proyectiles de honda hallados en las cercanías). Es un hallazgo de importancia por el tipo de armas hallado (entre ellas una espada de hoja recta del tipo del gladius hispaniensis y un puñal dobleglobular), su cronología a caballo entre el fin del mundo turdetano y la definitiva implantación romana, y la asociación cerrada de armas: espada, puñal, lanzas. Es posible que el conjunto deba datarse a principios del s. II a.C. y que por tanto la espada del Cerro de las Balas sea el más antiguo ejemplo de gladius hispaniensis romano conocido... o uno de los últimos de espada indígena. Se discute finalmente la cercanía de la necrópolis, y en particular de esta tumba al campo de batalla de época cesariana de Munda (45 a.C.), para concluir que con toda probabilidad se trata de dos acontecimientos totalmente independientes, y que el enterramiento es bastante más antiguo.

Iberian Iron-Age weapons are extremely rare in western Andalusia, due mainly to the absence of the normative cremation cemeteries typical of other areas in the Peninsula, cemeteries where nearly all of the approximately six thousand Iron Age weapons that we know have been documented. In this paper we present one of the very few exceptions to this rule: a 'warrior' burial found in the Iron Age cemetery cemetery at 'Cerro de las Balas' (or «bullets' hill», so known after the many sling projectiles found in the neighbourhood). This is an important find due to three facts: the type of weapons (among them a sword of the gladius hispaniensis type and a dagger of a very late Celtiberian or very early Roman type); the date, between the Late Iberian period and Early Roman rule; and the closed assemblage of weapons: sword, dagger and two javelins or short spears. It is quite possible that the burial is to be dated to the beginning of the second century $\mathrm{BC}$, and therefore that the sword found in it is the earliest known example of the Roman gladius hispaniensis sword... or the latest version of the Iberian prototype for it. Finally, we discuss the proximity of this burial to the caesarian battlefield of Munda (45 BC) to conclude that in all probability these are two completely independent events, the burial being probably much earlier.

\section{PALABRAS CLAVE - KEY WORDS}

Armas ibéricas. Armas romanas. Necrópolis turdetanas.

Iberian iron Age weapons. Roman Weapons. Iberian cemeteries.

\footnotetext{
* Trabajo realizado en el marco de los Proyectos PB97/0057 de la DGICYT y 06/0030/1997 de la Comunidad de
} Madrid. 


\section{EL YACIMIENTO}

La necrópolis de el 'Cerro de las Balas', en las cercanías de Écija (al Este de Sevilla) se sitúa en las terrazas generadas al sur del río Genil, en una zona de lomas suaves y tierras fértiles a unos nueve kilómetros al Sur-Sureste de la actual Ecija (Astigi), junto al lado derecho de la carretera comarcal Ecija-La Lantejuela, a la altura de su kilómetro 9,5, más cerca de la segunda población aunque todavía en el término municipal de la primera (Figura 1). El paraje, perteneciente al cortijo de El Garabito, es una loma sin nombre específico. Sin embargo, al otro lado (el oriental) de la carretera, y a unos trescientos metros de la necrópolis que ahora nos ocupa, se encuentra un cerrete que ha prestado nombre al conjunto: se trata del 'cerro de la Atalaya' o genéricamente 'Cerro de las Balas', así conocido por el gran número de glandes de honda de época romano-republicana que aparecen en toda la zona, perteneciente al cortijo de 'El Nuño', que es otro de los nombres que recibe el yacimiento' ${ }^{1}$. Es más que probable que esta sea ésta la ubicación del poblado al que corresponde la necrópolis a la que ahora nos referimos, porque la meseta superior esta cubierta de restos ibéricos y romanos, que parecen cubrir desde el periodo turdetano y hasta el s. V d.C ${ }^{2}$.

El conjunto arqueológico -poblado y necrópolis- se ubica en una zona rica y fértil, muy poblada en época antigua y relativamente cercana a muchas grandes poblaciones de época prerromana y romana republicana, como Corduba, Carmo e Hispalis, y desde luego en el entorno más inmediato de Urso (Osuna) y Astigi (Ecija), ambas a menos de una jornada de marcha al sur y al norte respectivamente.

La necrópolis es conocida desde hace décadas; ya en 1940 aparecieron dos esculturas de toros actualmente conservadas en Ecija, y el yacimiento ha venido siendo saqueado por furtivos hasta la actualidad, con la destrucción de al menos doscientas sepulturas o quizá más 3 . Como consecuencia de esta destrucción sistemática, en otoño de 1988 se llevó a cabo por parte de uno de nosotros (E.N.) una campaña de excavación de urgencia en la necrópolis, en el curso de la cual se documentó una cincuentena de enterramientos. Un primer y sucinto informe preliminar de los resultados vio la luz en su momento, y a él remitimos para mayo-

1 Además de 'Cerro de las Balas' (Nuñez, Muñoz, 1988) y 'El Nuño' (Duran, Padilla, 1990:104, núm. cat. 103), el área se conoce también como 'Cerro de la Atalaya', 'de las Infantas', 'del Tesorillo', etc., lo que a veces complica la cuestión de la denominación. La mayoría de los estudiosos locales prefiere denominar el conjunto de poblado-necrópolis a ambos lados de la carretera como 'El Nuño', mientras que la ubicación del poblado propiamente dicha sería la del 'Cerro de las Infantas' o 'de la Atalaya', mientras que para Ferreiro (1986-87) y Durán-Padilla (1990:70, n.cat. 13) la denominación del 'Carro de las Balas' se limitaría a unas elevaciones algo más al Este, donde se ubica el yacimiento de 'La Alcuza'(e.g. Ferreiro (1986-87, Mapa 1), contra lo que recoge R. Corzo (1973:Fig. 3 y p. 247) para quien el topónimo 'Cerro de las Balas' coincide, justo al Oeste del Cortijo del Nuño y junto a la carretera, con el 'Cerro de la Atalaya'o 'de las Infantas'. L.A. López Palomo (1999: 186-189) tampoco contribuye a clarificar las cosas al recordar que 'Bajo este topónimo [Cerro de las Balas] incluimos un conjunto de colinas situadas en las inmediaciones del cortijo de la Alcuza... Cerro de las Infantas, también se le conoce como 'Cerro de las Balas' y 'Cerro de la Atalaya'. A fin de no confundir aún más las cosas, hemos mantenido la denominación de 'Cerro de las Balas' dada a la necrópolis en el primer informe de excavación (Nuñez, Muñoz, 1988). En 1990 uno de nosotros (E.N.) Realizó una serie de prospecciones en el término municipal de Ecija empleando métodos magnéticos que permitieron identificar, en la zona más elevada del 'Cerro de las Balas', las trazas de una edificación rectangular de grandes proporciones.

2 Durán, Padilla (1990:104).

3 Ibidem pág. 104: "Producto de esta actividad fundamentalmente destructiva fue la extracción de unas doscientas urnas de las que pudimos rescatar ocho, una de ellas con todo el ajuar [...] El ajuar que contenía una de las urnas rescatada por nosotros se componía de una lucerna, una fíbula de horquilla y un vaso de paredes finas, materiales situables en su conjunto en época julio-claudia. Algo anterior puede ser la estela funeraria tallada en piedra caliza y representando dos figuras, muy probablemente hombre y mujer, también hallada en esta necrópolis.

Tanto en la zona de hábitat como en la necrópolis han sido abundantes los hallazgos de material metálico. Los que hemos podido controlar se concretan en fíbulas, ponderales, exvotos, glandes de plomo — algunos con la inscripción $G M$, sin paralelos conocidos-, espadas, puñales, herramientas agrícolas, botones, pasadores, falos, tuberías de plomo y monedas ibero-romanas, republicanas, denarios de Pompeyo, republicanas e imperiales". (la cursiva es nuestra) 


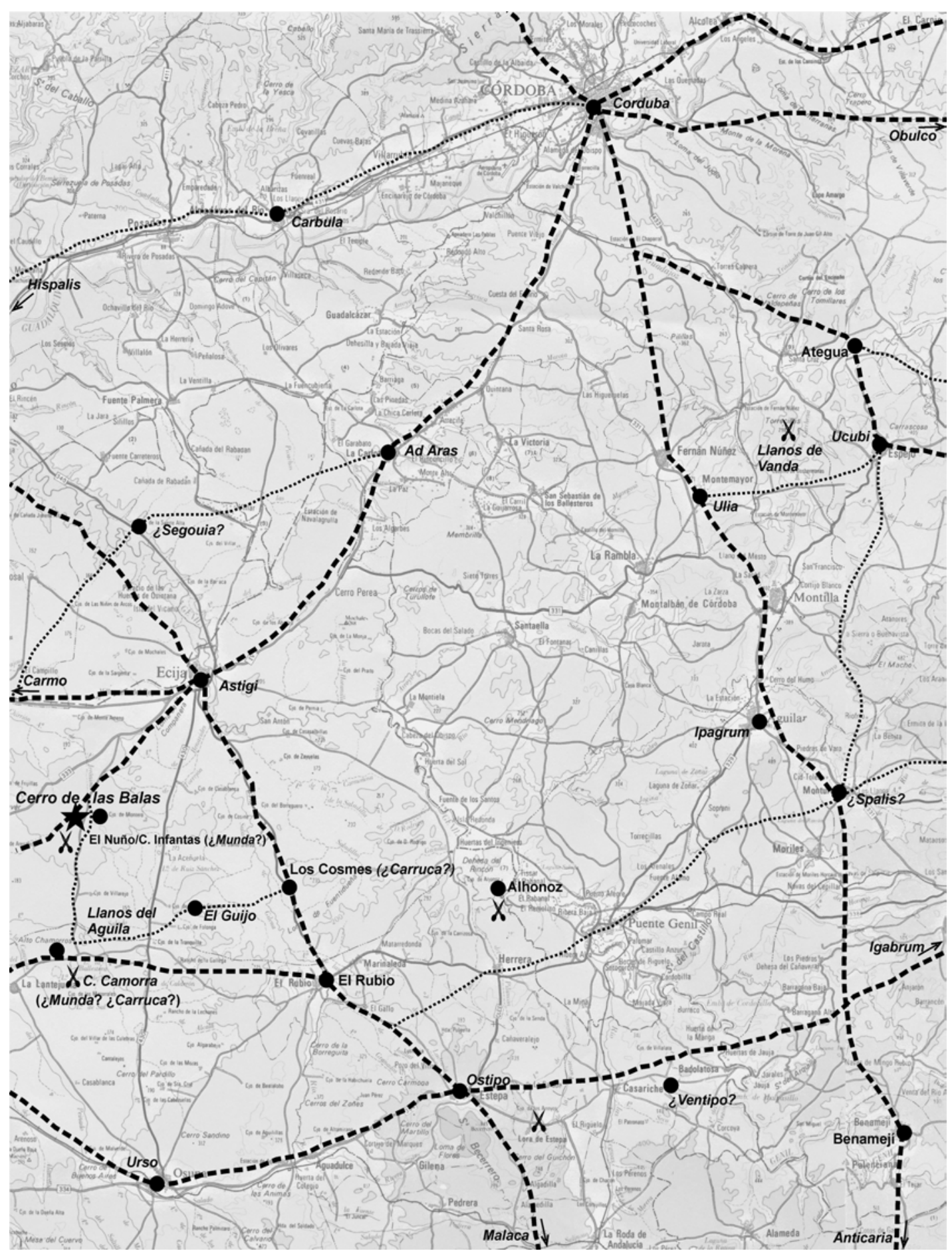

Fig. 1. Localización del yacimiento del Cerro de las Balas en su entorno general, sobre un mapa viario moderno e indicando las principales poblaciones de época romana republicana, época a la que pertenece la sepultura que se analiza. La red viaria romana, basada en la indígena, está construida a partir de los datos de G. Arias (1987), Roldán (1973), Melchor (1995), Durán y Padilla (1990), Corzo (1992 y 1973), y Ferreiro (1986-87). 


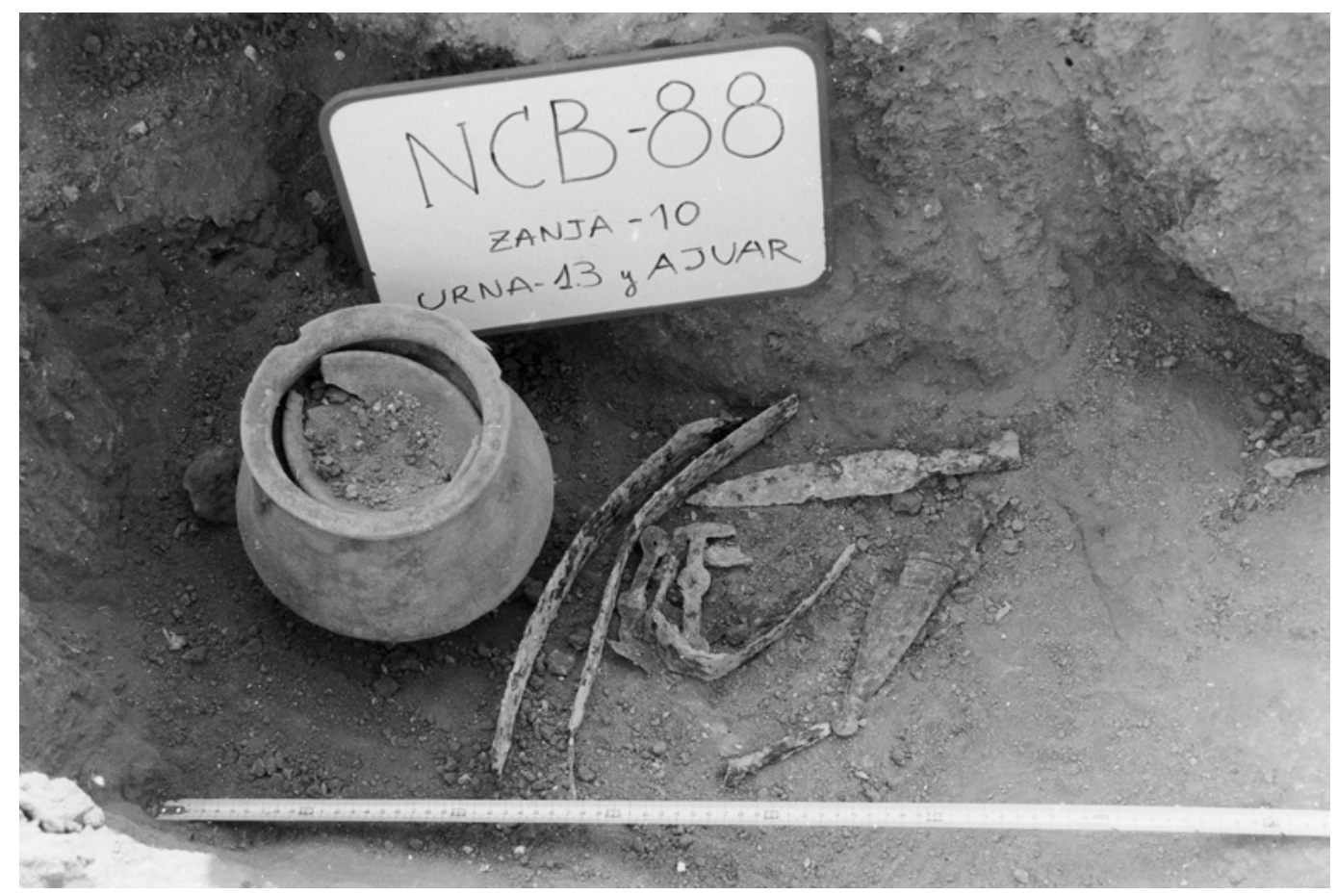

Lám. I. Sepultura 13 de la necrópolis del 'Cerro de las Balas’ (Foto E. Núñez).

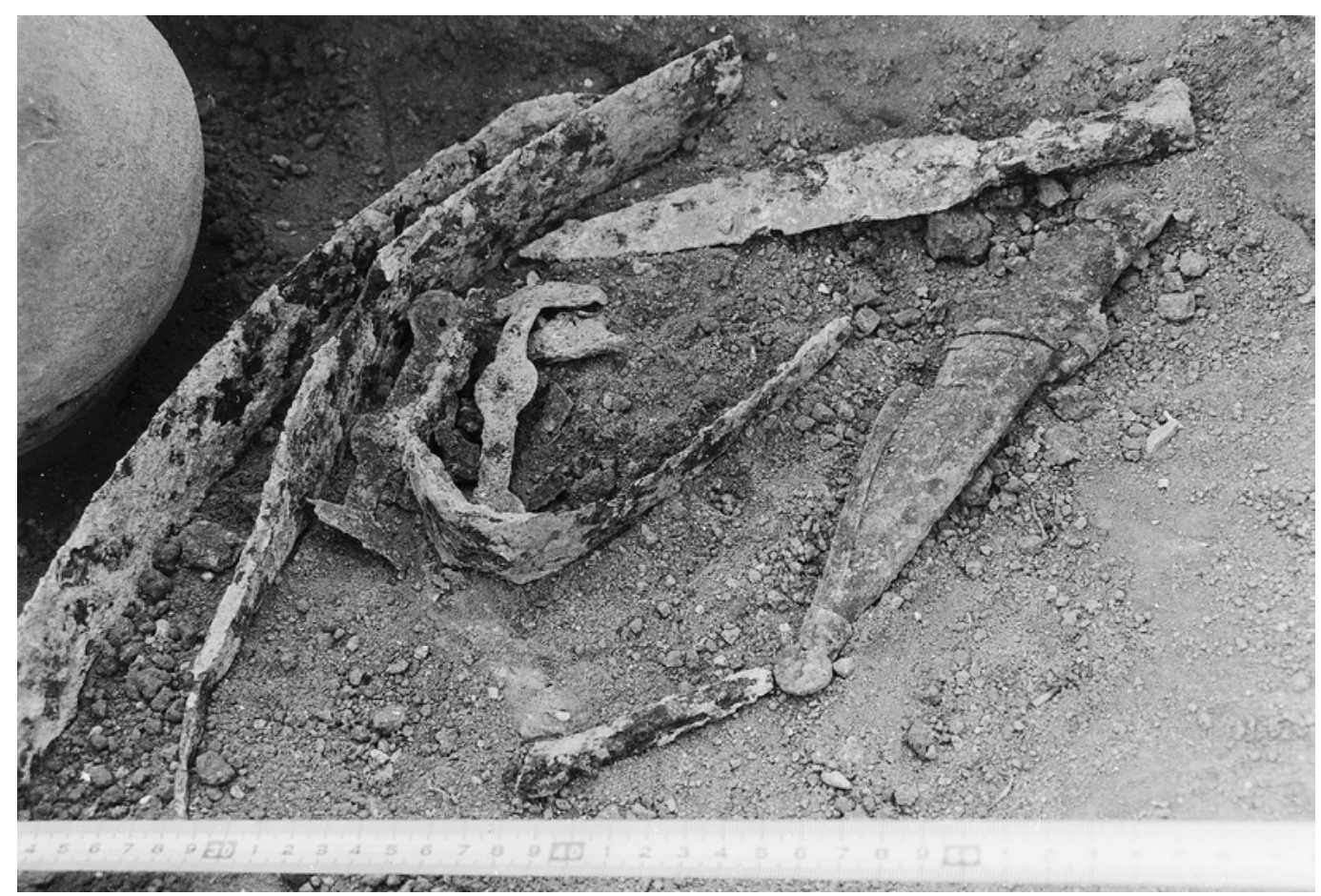

Lám. II. Detalle del ajuar metálico de la Sepultura 13 en el momento de su descubrimiento (Foto E. Núñez). 
res detalles en cuanto a la metodología de excavación, aunque convendrá recordar que los trabajos apenas si bastaron para delimitar el yacimiento y no pueden considerarse un trabajo en extenión ${ }^{4}$. Aquí nos bastará anotar algunos datos esenciales: todas las sepulturas halladas eran de cremación en urna sin señalización exterior aparente. Las urnas de cerámica ibérica, y el plato que a menudo las tapaba, se colocaron en pequeñas oquedades practicadas el efecto en la roca caliza de base. Dichos hoyos presentan diferentes variantes dentro de una gran sencillez. Los ajuares documentados en la excavación fueron sencillos, e incluyen sólo (aparte de la urna cerámica y su tapadera) vasos de pequeño tamaño, de tipología ibérica y romana, fusayolas y pesas de telar. En la cata 5 de la excavación se documentó además un pequeño toro ibérico de piedra (long. máx. $42 \mathrm{~cm}$.) que viene a unirse a los antes mencionados.

\section{LA SEPULTURA 13 (ZANJA 10)}

En este contexto de sepulturas sencillas de Baja Época Ibérica y/o época romanorepublicana llama la atención la Sepultura 13 de la zanja 10, no por su estructura sino por su ajuar. En primer lugar, la urna, de tipo ibérico con decoración pintada (Figura 2 y Lámina III) estaba cubierta por un cuenco de barniz negro (Figura 3 y Lámina IV), que en principio no se identificó como tal dado que estaba por completo cubierto con una espesa capa de concrecciones calizas que, como en otros muchos recipientes cerámicos del yacimiento ${ }^{5}$, dificulta o impide por completo la identificación de los tipos y de su decoración. Sólo tras la restauración de la pieza pudo identificarse como una pieza de barniz negro del tipo genéricamente conocido como 'campaniense' 6 . Junto a la urna 13 apareció un interesante ajuar metálico, cuyo análisis y valoración constituye el núcleo del presente trabajo, y que constituye una excepción entre los hallados en la mencionada excavación de urgencia, aunque, como se ha expresado en la nota 4, hay referencias a la aparición de otras armas en las cercanías, lamentablemente sin contexto arqueológico, y que no hemos podido examinar.

La urna 13 y su ajuar no aparecen aislados; antes bien, se hallaron junto a otras urnas cinerarias sin ajuar (urna 12, con restos posiblemente infantiles a juzgar por el tamaño de los restos óseos; urna 14), y todos a la misma profundidad, unos sesenta $\mathrm{cm}$. bajo la superficie actual del terreno.

1. Urna cineraria (Lámina III, Figura 2). Contenía restos cremados que no han sido hasta el momento objeto de análisis osteológico. Cubierta de espesas concrecciones, una vez restaurada se apreció una decoración bícroma; sobre fondo crema anaranjado aparecen dos gruesas bandas horizontales de color rojo vinoso en cuello y galbo, así como líneas horizontales y series de líneas onduladas verticales en negro. Sus dimensiones básicas son: $23,5 \mathrm{~cm}$. de altura y un diámetro de borde de16,6 cm. Formalmente, este tipo de recipiente corresponde estrechamente en forma y decoración con un ejemplar de urna hallado en Setefilla (Sevilla), también bícromo, que corresponde a la Forma XVII-B de J.L Escacena ${ }^{7}$, grupo que en todo caso recoge una excesiva variedad formal como para que sus otros ejemplares puedan considerarse paralelos cercanos a la pieza que ahora estudiamos. En todo caso, la urna del enterramiento I turdetano de Setefilla, muy próxima a la del Cerro de las Balas ${ }^{8}$, es fechada por Escacena entre los siglos II-I a.C. por similitudes con los esquemas decorativos de cier-

4 Nuñez, Tinoco (1988).

5 Nuñez, Muñoz (1988:431).

6 No hay por tanto duda de la asociación de este cuenco con la Sep. 13, pese a que por las fotografías se aprecie la presencia de un cuenco-tapadera de color blanquecino, debido, como se ha dicho, a las concrecciones.

7 Escacena (1986:556 ss. y Fig. 450).

8 Aubet (1981:218-219). 


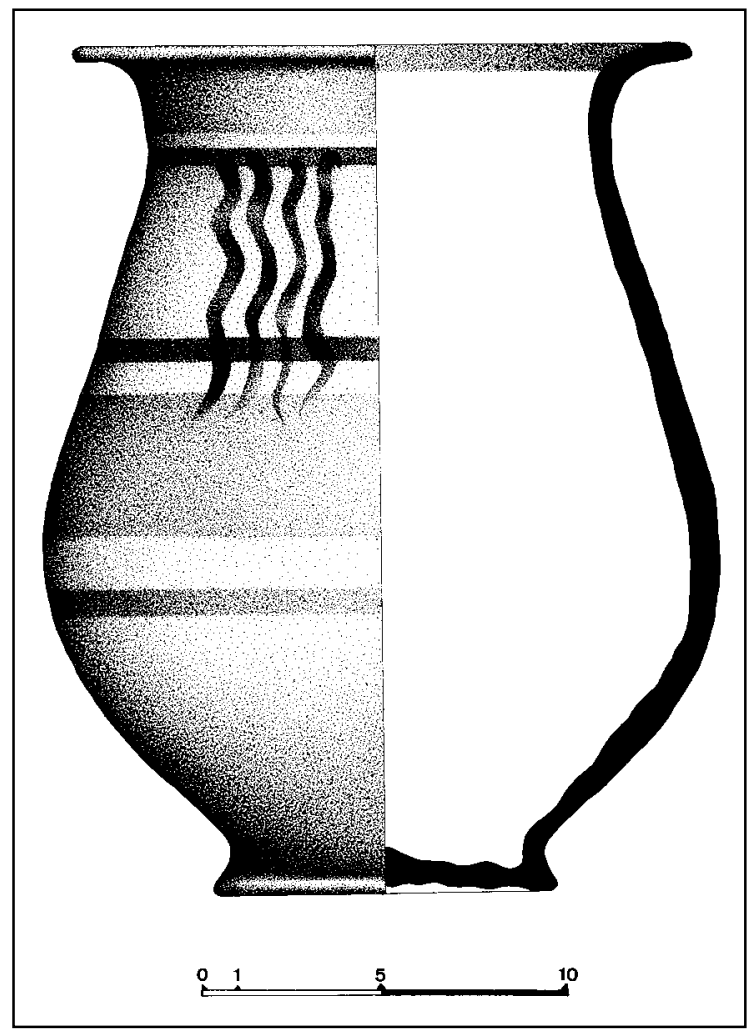

Fig. 2. Urna ibérica pintada de la Sep. 13.

Lám. III. Urna ibérica pintada de la Sep. 13 (Foto F. Quesada).

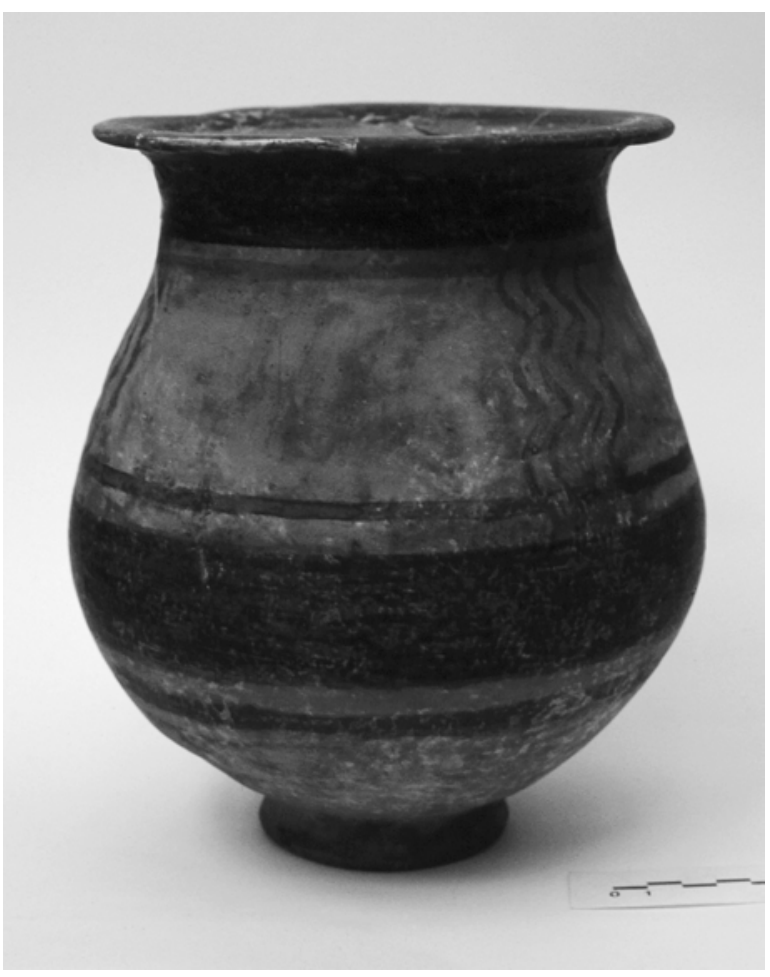


tas piezas del Pajar de Artillo en Sevilla9. Muy distinta es la solución de J. Pereira, para quien el vaso de Setefilla pertenecería a su grupo formal 6, datable sobre todo en el s. IV a.C., con perduración en el III; de hecho, data en el s. IV a.C. el vaso de Setefilla — pese a anotar que su decoración bícroma choca con la monocromía del resto de los vasos del gru$\mathrm{po}^{10}$. Creemos que con seguridad esta datación es demasiado antigua, tanto por el perfil del vaso, como por su sistema decorativo, como por los contextos en que aparecen las formas similares. Por último, el perfil y patrón decorativo de esta urna parecen asociables al amplio conjunto de material documentado por nosotros en el Cerro de la Cruz (Almedinilla, Córdoba), fechable en la segunda mitad del s. II a.C., por lo que la urna del Cerro de las Balas podría tentativamente fecharse entre principios del s. II a.C. y el s. I a.C., sin que sea posible mayor precisión en el estado actual de nuestros conocimientos ${ }^{11}$.

\section{Cuenco de barniz negro empleado como tapadera de la urna (Figura 3 y Lámina IV).}

La urna estaba cubierta por un cuenco completamente cubierto de concreciones (Lámina I) que, tras su restauración y limpieza, resultó ser un cuenco de cerámica de barniz negro clasificable dentro del grupo global de las 'campanienses' (Figura III y Lámina IV). La pasta, anaranjada, y el barniz negro, con irisaciones metálicas, entran dentro de las características habituales de la 'Campaniense A', lo mismo que la decoración, toda ella en el interior de la pieza y consistente en dos bandas horizontales estrechas y muy desvaidas que enmarcan una línea casi perdida de )hiedra?, todo ello realizado con pintura blanca. En el fondo del vaso aparece una gran roseta hexapétala. El diámetro máximo en la boca es de $15.2 \mathrm{~cm}$. El perfil es sustancialmente convexo, aunque con una ligera concavidad en la zona del labio. En particular, la roseta, característica de la forma $33 \mathrm{aL}$, presenta algunas peculiaridades frente a otros ejemplos: es compleja, como corresponde a una fase antigua de la Campaniense A, pero su zona central (con dos círculos concéntricos) y los elementos secundarios, como los estambres intermedios, son más descuidados de lo normal en estos vasos.

Todos estos rasgos, junto con la ausencia de un pie marcado, aproximan esta pieza al tipo 2154a de Morel (correspondiente al 33a de Lamboglia), fechado por el primero de estos autores en una fase Campaniense antigua en torno a principios del s. II a.C. o incluso ligeramente antes, muy a fines del s. III. Fechas dentro del s. II a.C. son las que acepta J. Ventura para rosetas similares, exclusivas de la forma $33 \mathrm{aL}$, en la Cuesta del Rosario en la cercana Sevilla ${ }^{12}$. Sin embargo, y según J. Ventura ${ }^{13}$ y E. Sanmartí, formas con estas características aparecen en la Península incluso después del 138 a.C., fecha de la fundación de Valencia, en incluso se conocen imitaciones realizadas en Campaniense $\mathrm{B}^{14}$. Una variante de esta forma 33L, pero ya con pie anular (Morel 2973a; Lamboglia 33b), sin roseta, y con o sin pintura blanca aparece en Campaniense A en fechas de finales del s. II a.C., pero también en Campaniense B, entre el 150 y el 25 a. $\mathrm{C}^{15}$.

Por otro lado, la forma L33a y su correspondiente roseta no aparecen entre la cerámica romana de los campamentos numantinos ${ }^{16}$, lo que parecería indicar que ya estaba fuera de uso hacia el 133 a.C., pues en cambio sí que aparece en esos campamentos su variante tardía con pie anular L33b.

\footnotetext{
Luzón (1973)

0 Pereira (1988:768 ss. y 919).

Vaquerizo, Quesada, Murillo (1992)

Ventura (1985:56 y Fig. 9.45)

Com. pers. y a quiena gradecemos sus comentarios.

Sanmarti (1978:47-48, núm. 4 y Lám. 105; pág. 77-78, num. 92).

DICOCER (1993:148 y 152)

Sanmarti, Principal (1997)
} 


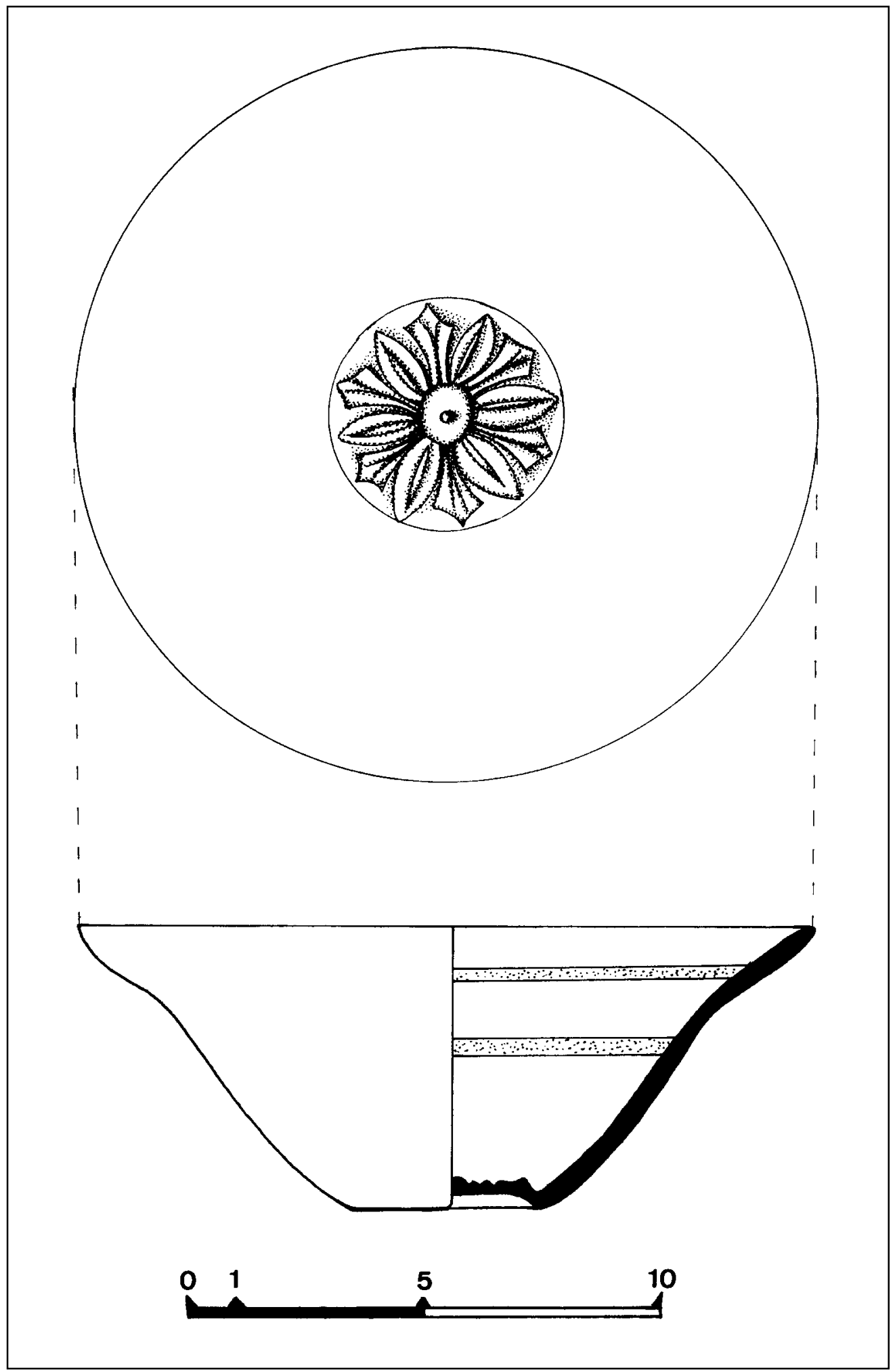

Fig. 3. Cuenco de barniz negro utilizado como tapadera de la urna. 


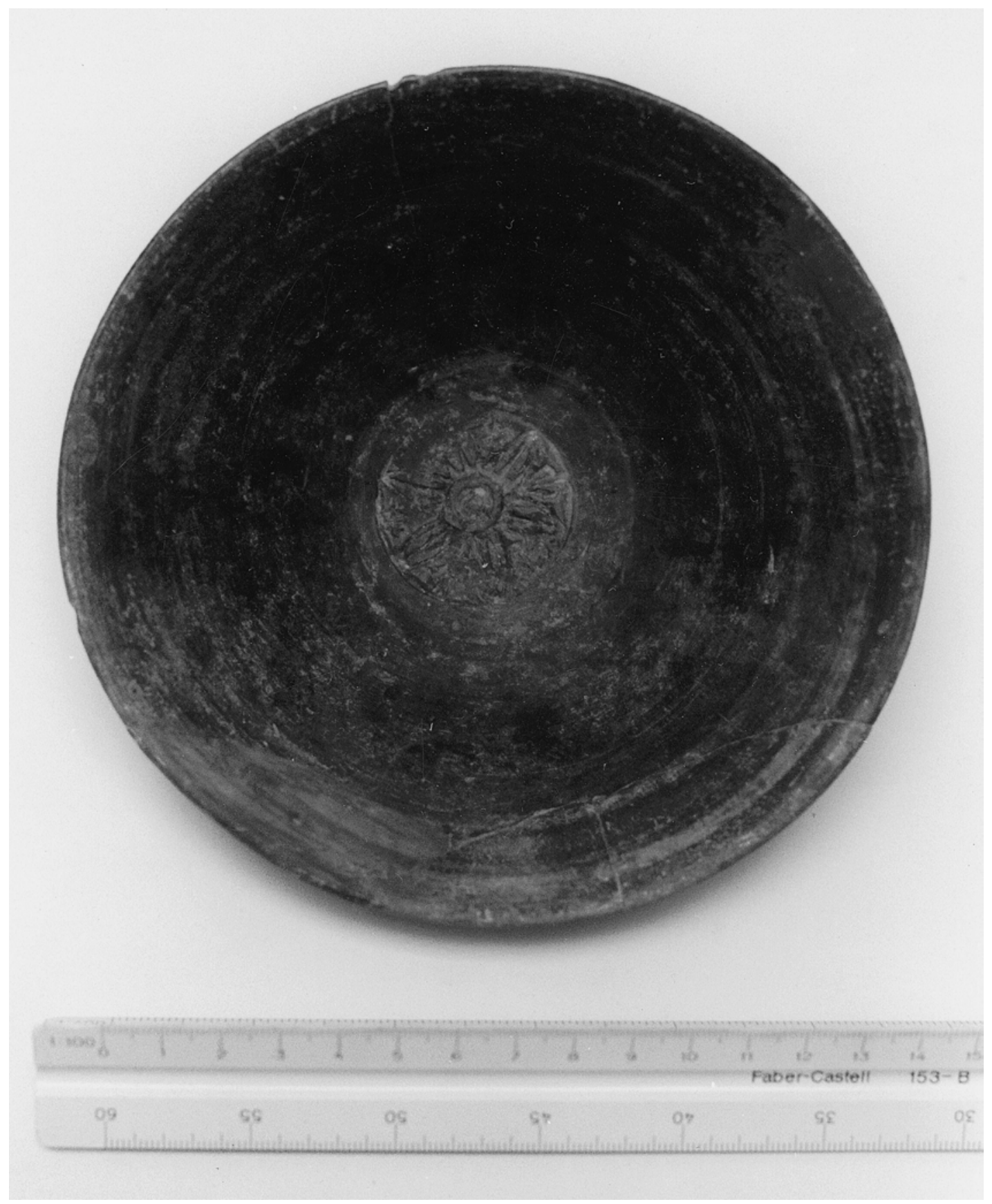

Lám. IV. Cuenco de barniz negro de tipo Campaniense colocado como tapadera de la urna 13 (Foto E. Núñez). 
En conjunto, la forma ápoda, el característico tipo de la roseta, y la pintura blanca nos llevan a una data de en torno a la primera mitad del s. II a.C. ${ }^{17}$ aunque hay detalles en el perfil algo sinuoso, trazado descuidado de la roseta y barniz que no nos hacen estar plenamente satisfechos y nos hacen pensar en el proceloso mundo de las imitaciones, tan mal conocido. En conjunto pues, sería forzar los datos disponibles si tratáramos de llevar esta pieza mucho más allá de mediados del s. II a.C., y muy difícil sobrepasar la frontera del s. I a.C. Otra cosa es que, tras una cierta —o larga - perduración, el cuenco acabara amortizado en una tumba posterior, cosa que es perfectamente posible y ha sido documentada ya en diversas necrópolis ibéricas como el Cabecico del Tesoro en Murcia.

\section{EL AJUAR METÁLICO.}

Pero sin duda lo más significativo de esta sepultura del Cerro de las Balas es su ajuar metálico, consistente en un lote de armas ofensivas.

\section{Espada de hoja recta (Figura 4, Láminas $V$ y VI) ${ }^{18}$.}

Espada muy doblada en forma de 'U' y luego partida en dos trozos antes de ser depositada en la sepultura, según se aprecia por su disposición en la tumba (Láminas I y II). Se observa además que fue colocada, junto a la urna, de filo sobre el terreno una vez doblada y partida. Corrosión superficial intensa, y muy acusada en la zona de la punta, que está perdida, aunque es posible estimar con bastante precision las dimensiones originales. Midió en total unos $77 \mathrm{~cm}$. de longitud, siendo la longitud de la hoja de unos $64 \mathrm{~cm}$. La anchura máxima de la hoja se da en los hombros, con $5.3 \mathrm{~cm}$. Su perfil de hoja es muy ligeramente pistiliforme, estrechándose muy ligeramente en la parter central y ensanchando de nuevo ligeramente hacia la punta. Los hombros son oblícuos a la espiga de la empuñadura, y ligeramente redondeados. La sección de la hoja es lenticular, y no se aprecia una arista central marcada que la divida en cuatro mesas, y menos aún restos de estrías o acanaladuras superficiales. No se conservan las cachas de la empunadura, que serían de materia orgánica, pero sí la espiga, de sección rectangular aplanada, y de casi $13 \mathrm{~cm}$. de longitud.

Tampoco se conserva resto alguno de la vaina, y teniendo en cuenta que, por el contrario, el puñal que acompaña a la espada (vid. infra) sí fue enterrado con la suya, cabe razonablemente suponer que se trató de una vaina fabricada por completo en materia orgánica como cuero o madera. Sin embargo, teniendo en cuenta que tampoco se documentó en la excavación ningún elemento de suspensión, cabe pensar que al doblarse y partirse el arma desenvainada, no se depositara la vaina completa.

Del conjunto de estas características se deduce claramente que no nos encontramos propiamente ante una espada 'de La Tène', tal y como habría sido clasificada hasta hace pocos años, sino ante lo que podríamos considerar el prototipo hispano del gladius hispaniensis romano o, incluso, propiamente ante una espada romana republicana (esto es, el propio gladius hispaniensis), tipo que ha sido objeto de varios estudios muy recientes que han aclarado considerablemente su problemática ${ }^{19}$.

17 Véase a título de comparación la forma similar de Sanmarti (1978:324, Lám. 8, núm. 92). Forma 33a L Ampurias, fechable entre fines del s. III y el II a.C. Sanmarti cree que la forma 33a fue imitada en Camp. B, pero sin roseta en el fondo (ibidem p. 78). Otra roseta similar (n.289, págs. 338 y 129 fue fechada por Sanmarti a fines del s. III-ppios. del II a.C.

18 Catalogada en Quesada (1997:855) con el núm. cat. 5362.

19 En particular, Quesada (1997a:248-273), (1997b), (1997c); Connolly (1997); Iriarte et al. (1996), (1997); Horvat (1997). 

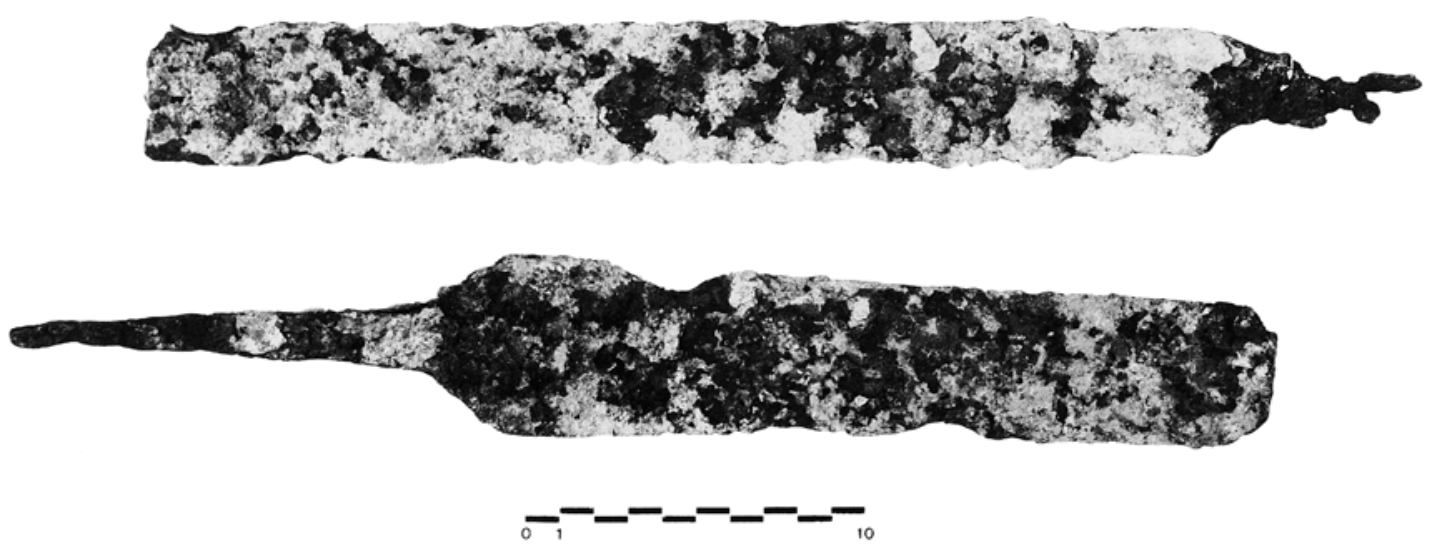

Lám. V. Espada de hoja recta (Foto F. Quesada).

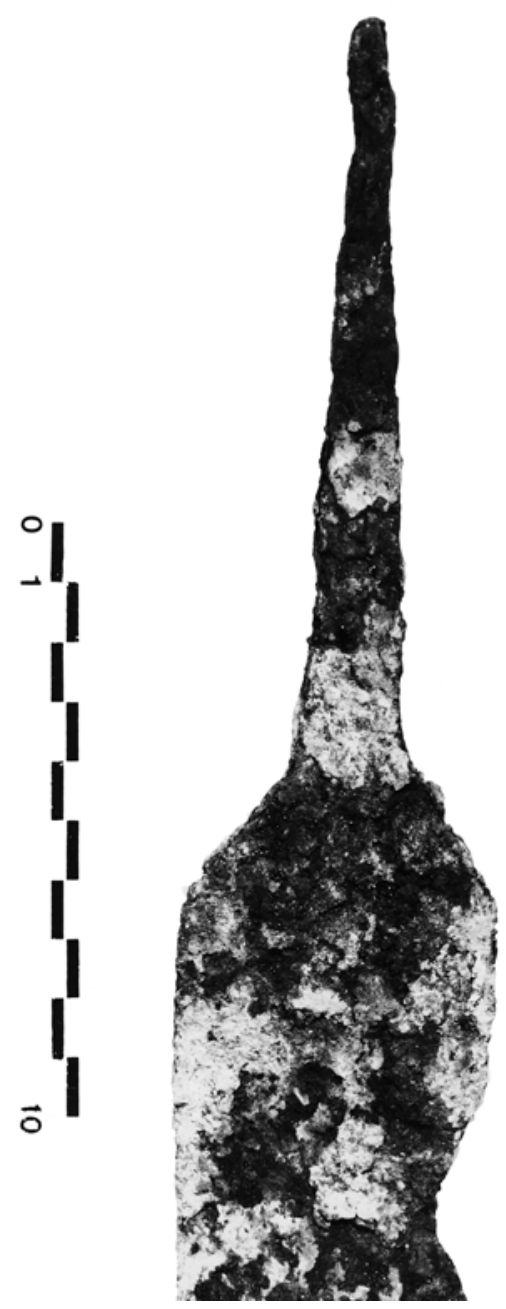

Lám. VI. Espada de hoja recta. Detalle de la empuñadura (foto F. Quesada). 


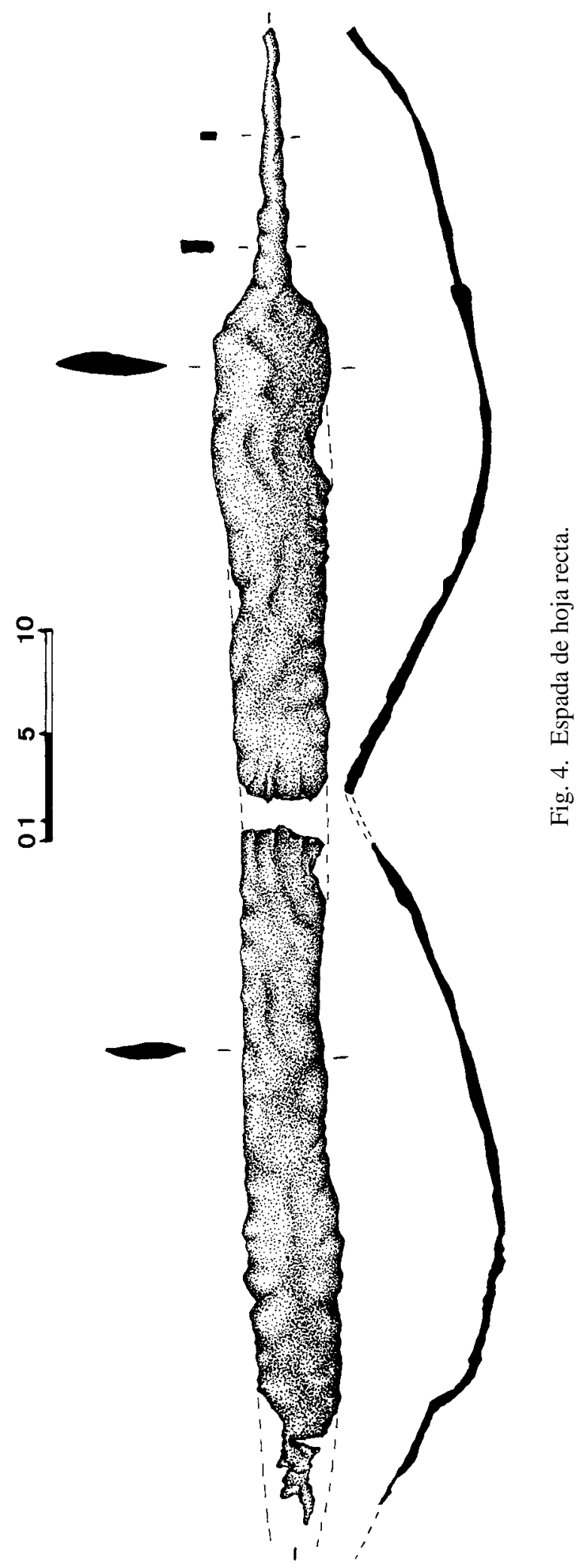


En síntesis, se trata a nuestro juicio bien de una espada indígena hispana de nuestro tipo $\mathrm{VIIC}^{20}$, bien de una espada romana republicana, de un gladius hispaniensis. En realidad, y según nuestra opinión ${ }^{21}$ tipológicamente estas armas serían indistinguibles, y sólo su lugar de fabricación y su portador permitiría adscribirla al ámbito romano o al indígena de época romana republicana 22 .

Las espadas VIIC son versiones hispanas (ibéricas y celtibéricas) de las antiguas espadas galas de La Tène I, pero de época más tardía (siglos III-II normalmente), fabricadas en la Península cuando el tipo ya había caido en desuso en Galia, y con un sistema de vaina y suspensión de tipo mediterráneo (vaina de madera o cuero con anillas para suspensión mediante tahalî) y no de tipo céltico (con vaina metálica enteriza y pontet o pasador fijo para un cinturón). En resumen: justo como las espadas romanas republicanas a nuestro parecer morfológicamente idénticas al tipo VIIC del que derivan (y no de las espadas cortas celtibéricas como hasta ahora se creía) ${ }^{23}$.

Las dimensiones de la espada que ahora tratamos encajan bien con las espadas peninsulares de nuestros tipos VIIB, VIIC y VIID (que marcan la evolución desde los prototipos celtas de La Tène I hasta las espadas rectas peninsulares derivadas de aquellas (VIIB), y que a su vez son el prototipo del gladius romano republicano-VIIC). Esta proximidad queda demostrado con un vistazo a las dimensiones comparadas de espadas indígenas (con una longitud de hoja entre 52 y $63 \mathrm{~cm}$., frente a los 64 de la del Cerro de las Balas) ${ }^{24}$, así como a los perfiles y secciones.

Pero las dimensiones y el perfil ligeramente pistiliforme encajan aún mejor con las espadas romanas republicanas, que oscilan entre los 60 y los $68 \mathrm{~cm}$. de longitud de hoja y rondan los $5 \mathrm{~cm}$. de anchura máxima (Figura 5). Sin embargo, las espadas romanas presentan habitualmente una sección romboidal aplanada con arista central más o menos acusada, que parece ausente en nuestro ejemplar ${ }^{25}$.

Aunque se ha insistido en que el perfil ligeramente pistiliforme es característico de este tipo de espadas romanas, e incluso en que la vaina de armazón metálico se asocia a este tipo de hoja, lo cierto es que creemos haber demostrado satisfactoriamente que una vaina de armazón no implica una hoja adelgazada en el centro (i.e., falcatas, espadas de antenas peninsulares), y a la inversa, que una hoja pistiliforme no necesariamente exige una vaina de armazón ${ }^{26}$. Dicho esto, lo cierto es que las espadas romanas de este periodo a menudo - pero no siempre - presentan un ligero y característico adelgazamiento en la zona central de la hoja, asociado a una punta triangular marcada, como ocurre en alguna de las espadas de Alfaro, Smihel o Giubiasco ${ }^{27}$. En este sentido, la espada del Cerro de las Balas sería también muy típica de un periodo en torno a la primera mitad del s. II a.C. en la reconstrucción tentativa propuesta por P. Connolly, para quien los gladii de Smihel (datados circa 175 a.C.) serían

20 Quesada (1997a:255).

21 Quesada (1997a,b,c).

22 De ahí el aparentemente alambicado título de nuestro artículo: la Baja Epoca Ibérica es también la época romana republicana, y en Andalucía durante los ss. II-I a.C. se pueden usar ambos términos, empleándose uno u otro según el contexto. En este caso parece primar el contexto indígena, pero tratándose de una tumba con armas, cuyo propietario pudo bien haber servido en el ejército romano, el panorama se hace más difuso, y la distinción, más resbaladiza.

23 En lo que viene a coincidir ahora expresamente P. Connolly, inicialmente reacio (Conolly, 1997: 56).

24 Para mayores detalles, ver Quesada (1997a:266-268, figs. 168 y 169) y (1997b:256-257).

25 De todas formas, la figura de Connolly (que reproducimos aquí) enfatiza quizá en exceso la arista central, lo que se hace evidente si comparamos su dibujo con el de Horvat sobre las mismas piezas. Connolly (1997:52), Horvat (1997:114).

26 Quesada (1997b:261).

27 Alfaro: Iriarte et alii (1997:250).Smihel: Horvat (1997:114, fig. 10.2); Giubiasco: Connolly (1997:51, Fig. 8.2). Sin adelgazamiento Mouries, Boyer, Berry-Bouy (Quesada, 1997b:261 y Fig. 4); Feugere (1994:14). Contra Connolly (1997:49) para quien la espada de Boyer, más que 'tapering' y acabada en punta triangular es 'waisted'. 


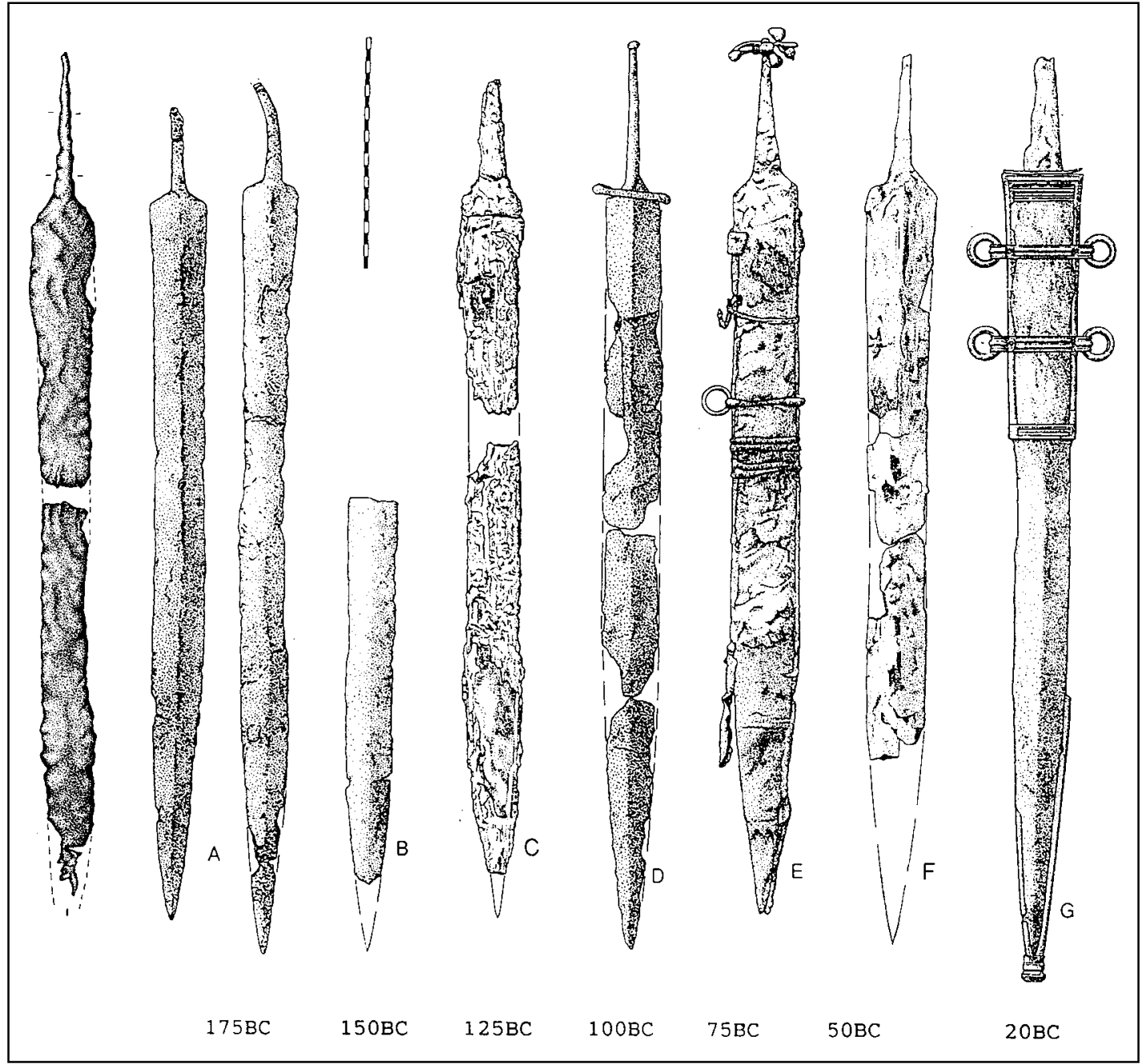

Fig. 5. La espada del Cerro de las Balas (izquierda) en comparación con el cuadro evolutivo del Gladius Hispaniensis romano propuesto por P. Connolly (1997). Otras espadas halladas en contextos puramente peninulares del s. III a.C. entrarían perfectamente a la izquierda de la figura. A. Smihel (Eslovenia). B. Campamento de Renieblas (Numancia). C. Es Soumaa (Argelia). D. Mouries (Francia). E. Delos (Grecia). F. Osuna (Sevi1la). G. Berry-Bouy (Francia).

los más antiguos conocidos. Con sus $64 \mathrm{~cm}$. de hoja, su ancho de $5.3 \mathrm{~cm}$. descendiendo hasta los 4 en el centro y sus hombros oblicuos, la espada de Ecija se compara perfectamente con las eslovenas ${ }^{28}$; si además aceptamos directamente la fecha más antigua que puede proporcionar la forma L33a asociada en el ajuar de la tumba (transición entre el s. III y el II a.C.), podría ser aún algo más antigua que las del depósito esloveno, y por tanto el primer ejemplar conocido de gladius hispaniensis... o uno de los últimos de espadas de tradición ibérica.

28 Horvat (1997). Ver respecto a las dimensiones las observaciones de Connolly (1997:50), que podrían haber sido escritas para la espada del Cerro de las Balas. La espada de Osuna, más ancha y masiva, es cesariana. 


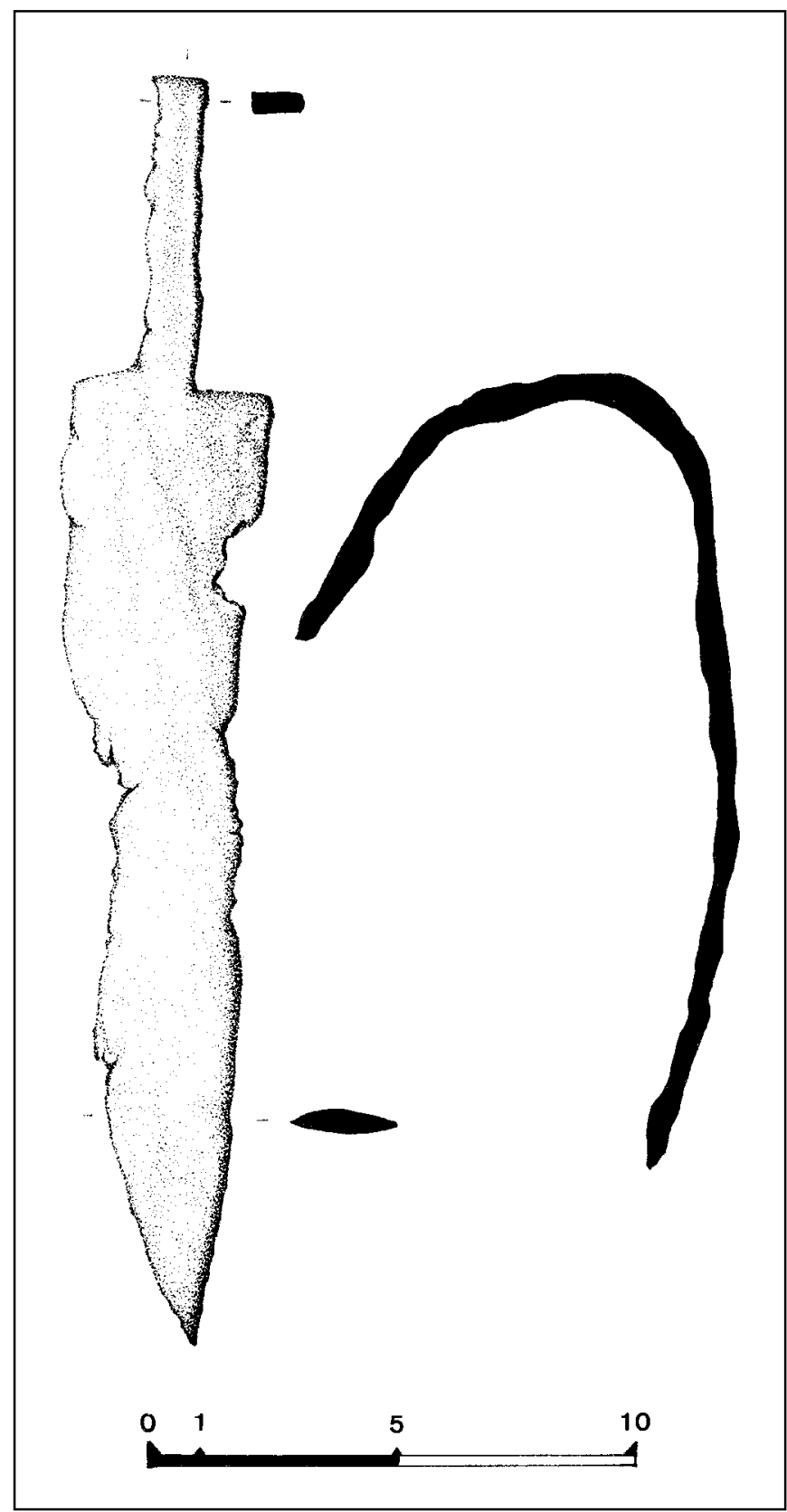

Fig. 6. Hoja del puñal. No es posible apreciar si la hoja era pistiliforme o no, como tampoco la existencia de un nervio central. 


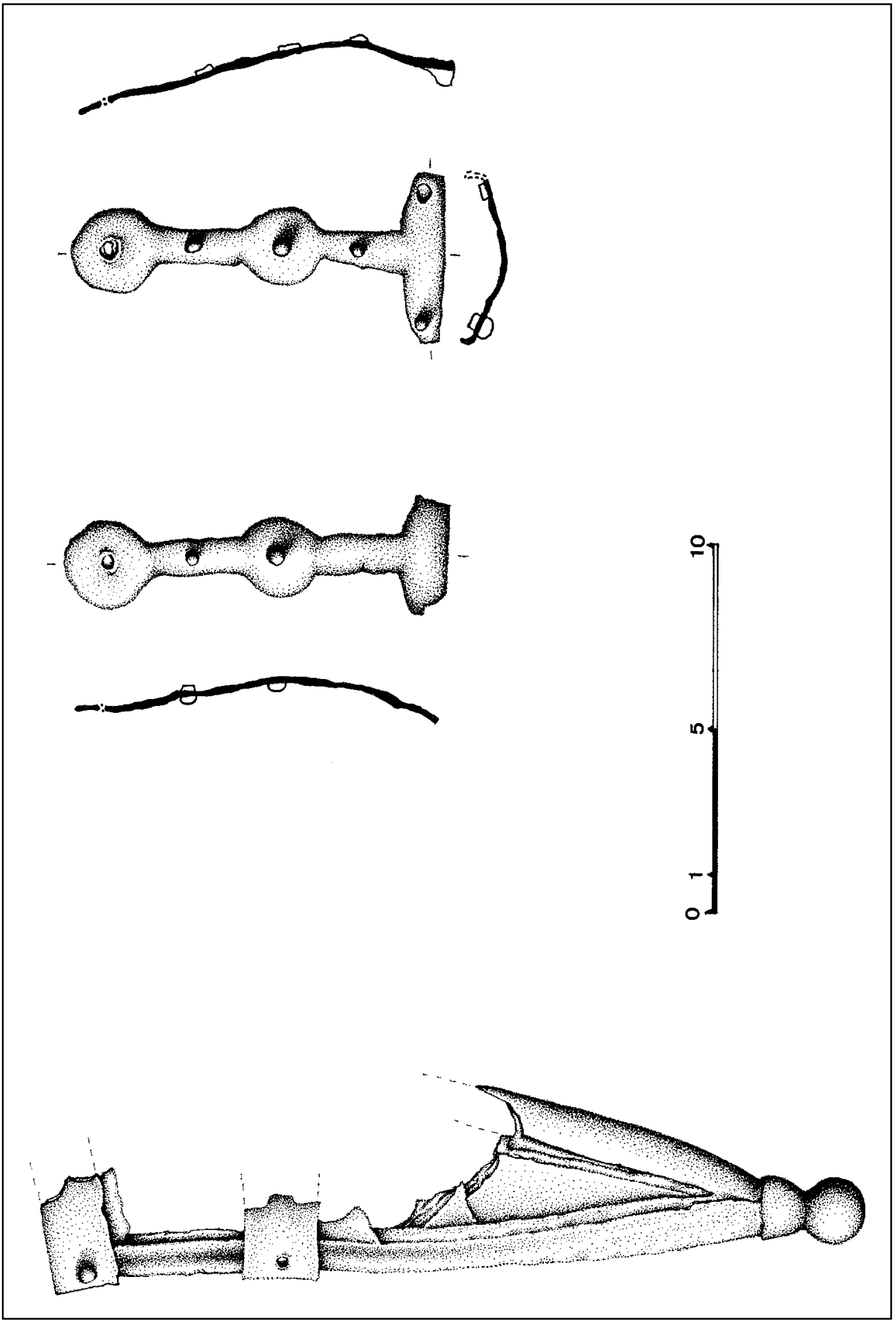

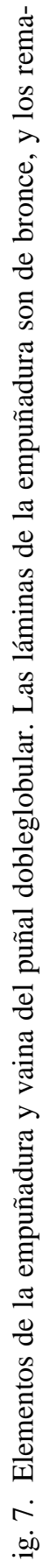


Lamentablemente, la zona de la punta está muy corroida y no es posible apreciar si, como ocurre en otros casos, se conformaba un extremo triangular aguzado, o si éste era más redondeado, de acuerdo con la tradición ibérica más antigua.

Por tanto, y en resumen, las características morfológicas de la espada del Cerro de las Balas parecen encajar bien con una fase antigua de la panoplia romana republicana en torno al final de la II Guerra Púnica, o con una avanzada de la ibérica, en torno a la primera mitad del s. II a.C. Esto, por otra parte, coincide muy bien con la datación independiente que parece en principio proporcionar la cerámica campaniense, quizá de principios del s. II a.C. (Campaniense A antigua) aunque bien pudo amortizarse en fecha posterior. Si eso es así, nos encontraríamos quizá ante uno de los ejemplos más antiguos de gladius hispaniensis romano, junto con los del depósito de Smihel en Eslovenia ${ }^{29}$. Desde luego, el tipo de espada al que corresponde la del Cerro de las Balas es de uso mixto, tajante y puntante, capaz de producir los terribles efectos que Tito Livio describía (Livio, 31, 34).

\section{Puñal de hierro dobleglobular con vaina de armazón de bronce (Figuras 6 y 7, Lámi- nas VII-IX).}

En la Sep. 13 se halló también un puñal ${ }^{30}$. Según se aprecia en las Láminas I y II, estaba doblado en forma de ' $U$ ', y en el proceso de descomposición de las cachas se desprendieron las piezas de bronce que formaban el conjunto de la empuñadura. El puñal se depositó desenvainado, y la vaina se colocó a pocos centímetros.

Se trata de un característico puñal con empuñadura dobleglobular de tipo 'celtibérico'31, aunque, y como ocurre con la espada que hamos analizado en párrafos anteriores, también podría ser considerado como 'romano'. La hoja, muy corroida y deformada (Figura 6, Lámina VII) mide $20 \mathrm{~cm}$. de longitud y tiene una anchura máxima, en los hombros, de $4.2 \mathrm{~cm}$. Los hombros son perpendiculares a la empuñadura, como es por otra parte habitual en este tipo de puñales. La espiga o lengüeta aplanada mide $6.8 \mathrm{~cm}$. El puñal completo, de pomo a punta, debía medir unos $29.5 \mathrm{~cm}$. La hoja no evidencia rastros del nervio central ni de la hoja acusadamente pistiliforme característica de los puñales romanos tanto de época republicana (Numancia, Cáceres el Viejo...) como de época Augustea. Sin embargo, también es cierto que en los campamentos numantinos hay algunos puñales con hoja apenas adelgazada en el centro y sin nervio, similares a la que aquí presentamos, y que incluso en época sertoriana, hacia el 80 a.C., siguen apareciendo en contextos romanos puñales sin estrechamiento central de la hoja (Figura 8.D) ${ }^{32}$.

La empuñadura constaba de una lengüeta de hierro solidaria con la hoja que actuaba de alma para unas cachas perdidas de material orgánico, a las que a su vez se remachaban dos placas exteriores de bronce con el característico sistema de dos discos, uno en el centro del puño para facilitar el agarre, y otro en el pomo (Láminas II, VIII, Figura 7). Estas placas se sujetaban a las cachas y al alma central del puño mediante un total de seis remaches de hierro, dos en la guarda y cuatro alineados a lo largo de la empuñadura, incluyendo uno en el centro de cada disco. Las placas no presentan decoración visible, aunque por su mal estado de conservación no se puede excluir que contara con algún tipo de motivos incisos lineares simples. En todo caso, de lo que no cabe duda es de que carecía de la rica decoración que encontramos en los puñales celtibéricos típicos de la meseta (que a veces incluye el uso de aplicaciones de oro) ${ }^{33}$. Por supuesto, tampoco presenta la rica ornamentación propia de algu-

\footnotetext{
29 Horvat (1997:passim); Connolly (1997:41).

30 Num. catálogo 5367 de Quesada (1997).

31 Sobre este tipo de puñal, síntesis más reciente en Quesada (1997a:292 ss.). Sobre la adopción del puñal celtibérico por los romanos en torno a mediados del s. II a.C., Quesada (1997a:300 ss.) y Connolly (1997:56-57).

32 Ver también Bishop y Coulston (1993:54); Ulbert (1984:Tafel 25).

33 Cabre de Moran (1990:221).
} 
nos puñales romanos de época augustea ${ }^{34}$. Los dos discos son circulares, un indicio de cierta antigüedad desde una perspectiva romana pues, como es sabido, en época augustea el pomo discoidal se transforma en achatado o en media luna. ${ }^{35}$

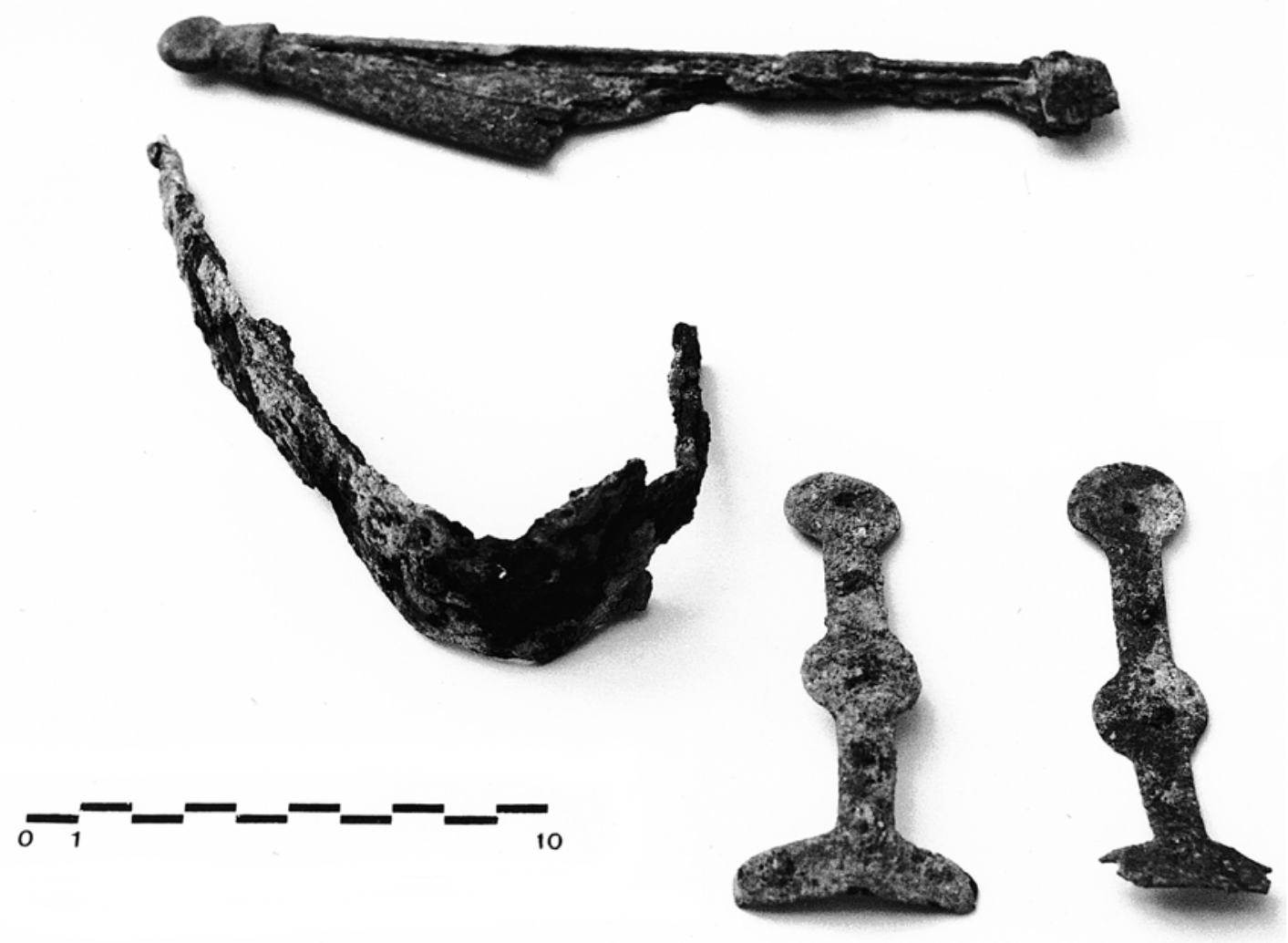

Lám. VII. Conjunto de elementos de puñal de empuñadura dobleglobular y su vaina (foto F. Quesada).

La vaina es relativamente poco habitual en tanto que toda su estructura es de bronce (Lámina IX, Figura 7). Está realizada con el habitual sistema de un armazón de varillas con sección en 'U' que abrazan una lámina de bronce aparentemente no decorada y dos puentes también de bronce sujetos por remaches de hierro. Mientras que es normal que los puentes y las láminas de recubrimiento se hicieran de bronce ${ }^{36}$, es más raro que también el armazón de varillas sea broncíneo, pero no inusitado: al menos desde el s. IV a.C. se conocen ejemplos de esta técnica en el Norte de la Meseta ${ }^{37}$. El conjunto de la vaina se remata, a modo de contera, con un botón esférico embutido en el resto de la estructura mediante un capuchón cónico.

En conjunto, el puñal no se adapta a los tipos más antiguos de puñal dobleglobular celtibérico, propios del s. III a.C. ${ }^{38}$, pero tampoco a los romanos de época augustea. Aisladamente, y sin tener en cuenta su propio contexto, cabría fecharlo pues entre el s. II y el I a.C., donde

\footnotetext{
34 Bishop, Couslton (1990:Fig. 39.1; Lám. 1).

35 Ibidem Fig. 39; Cabré Herreros, Morán Cabré (1991); Quesada (2000).

36 Cabre (1990:221).

37 E.g. Filloy, Gil (1997.144).

38 Quesada (1997:273 ss.).
} 
encontraría buena compañía en otros puñales similares (Figura 8). Con todo, la tendencia recta del perfil de la hoja y la ausencia de nervio central marcado podrían apuntar hacia una fecha antigua dentro de este intervalo. Así pues, una datación independiente conviene bastante bien con la de la espada y la cerámica.

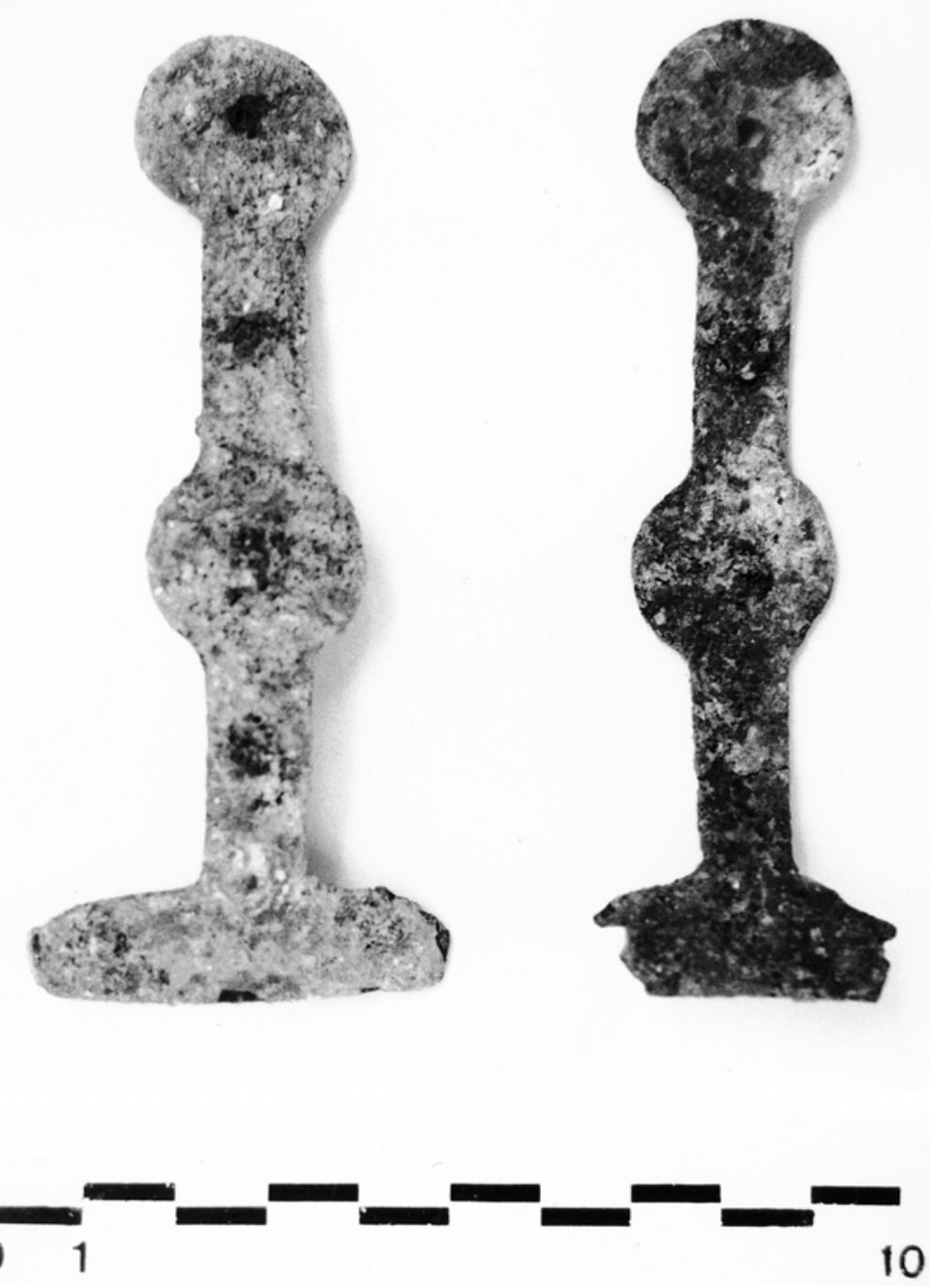

Lám. VIII. Detalle de la empuñadura del puñal. 


$$
1
$$




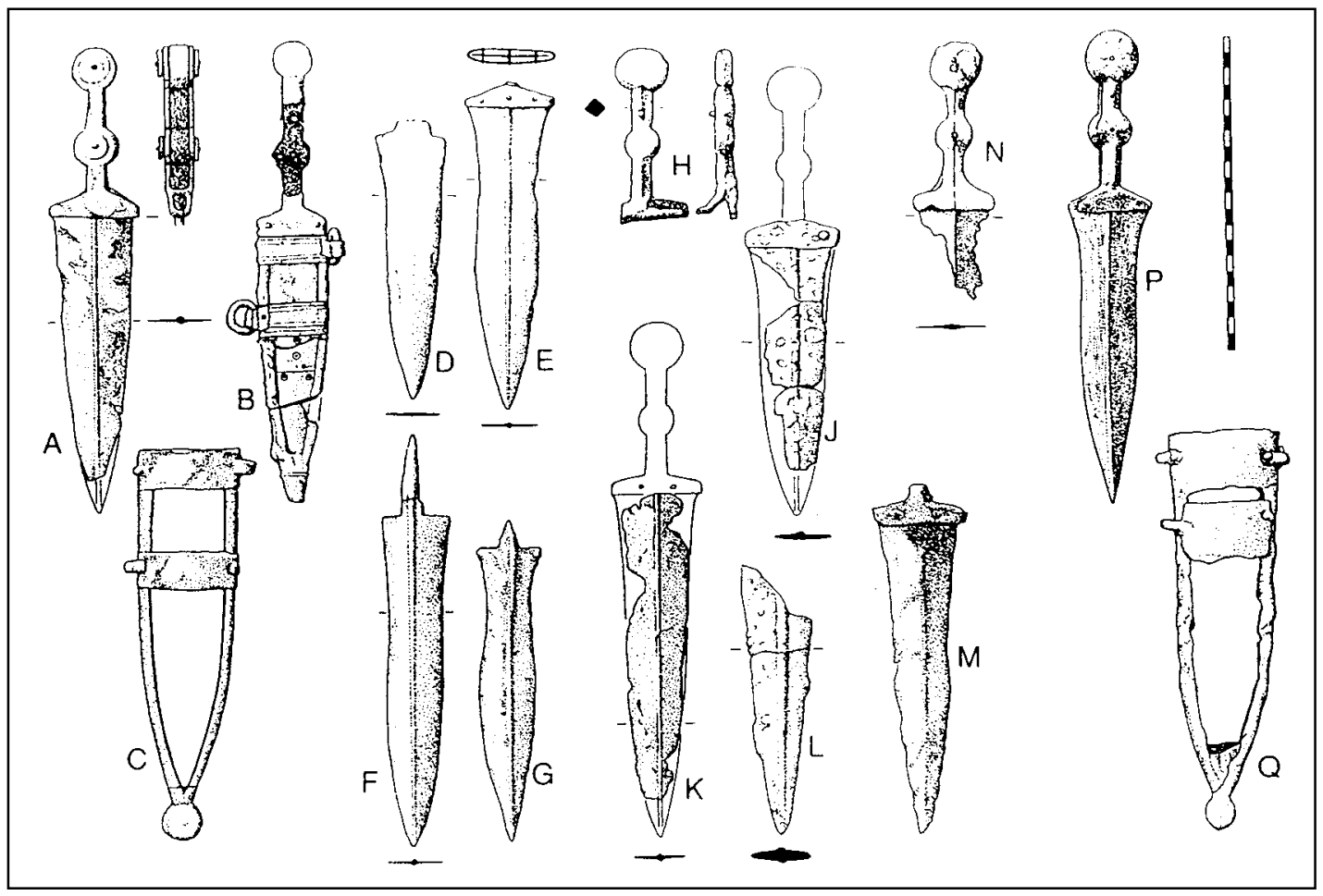

Fig. 8. Propuesta de evolución de tipos de puñales dobleglobulares de época romana republicana. A. Quintanas de Gormaz (necrópolis indígena). B. Numancia (época romana), C. Vaina de puñal de Ciruelos (Guadalajara). D-G. Campamentos de Numancia. H-L. Campamento de Cáceres el Viejo. M. Alesia (Galia). N. Zona del Sanona (Francia). P. Oberaden en Alemania. Q. Vaina de Exeter (Inglaterra). Se aprecia la ausencia de línaes evolutivas claras.Según P. Connolly (1997).

\section{5 y 6. Puntas de lanza pequeña o de jabalina (Figura 9 y Lámina X).}

Completan el ajuar de esta sepultura dos puntas de jabalina o de lanza pequeña, carentes al parecer de regatones. La primera (Figura 9, izquierda) ${ }^{39}$ corresponde a nuestro tipo Quesada 8 a (variante VIIBa). Falta la punta y parte del cubo, pero se pueden estimar las dimensiones originales en torno a los $25 \mathrm{~cm}$., con una longitud de hoja de $18 \mathrm{~cm}$. La anchura máxima de la hoja, en la zona central-proximal, es de $3.4 \mathrm{~cm}$. La sección es lenticular muy aplanada, sin ningún tipo de nervio ni arista central visible. Conservación regular-mala, muy exfoliada, faltando el extremo de la punta y parte del cubo. Sin doblar.

La segunda punta (Figura 9 derecha) ${ }^{40}$ pertenece, con sus filos más paralelos a lo largo de toda la moharra, al tipo Quesada 9a (variante VIIBb). Más completa que la anterior, mide $23.5 \mathrm{~cm}$., con una longitud de hoja de $17 \mathrm{~cm}$. y una anchura máxima de 3.6 , mantenida a lo largo de buena parte de la misma. La sección es lenticular muy levemente aristada, marcando apenas las cuatro mesas. Por tanto, se parece mucho en dimensiones, peso, sección y capacidad perforante a la pieza anterior, aunque el aspecto de la hoja sea más ancho. Conservación regular. Sin doblar.

\footnotetext{
39 Quesada (1997a:num. cat. 5364).

40 Quesada 81997a:núm. cat. 5363).
} 

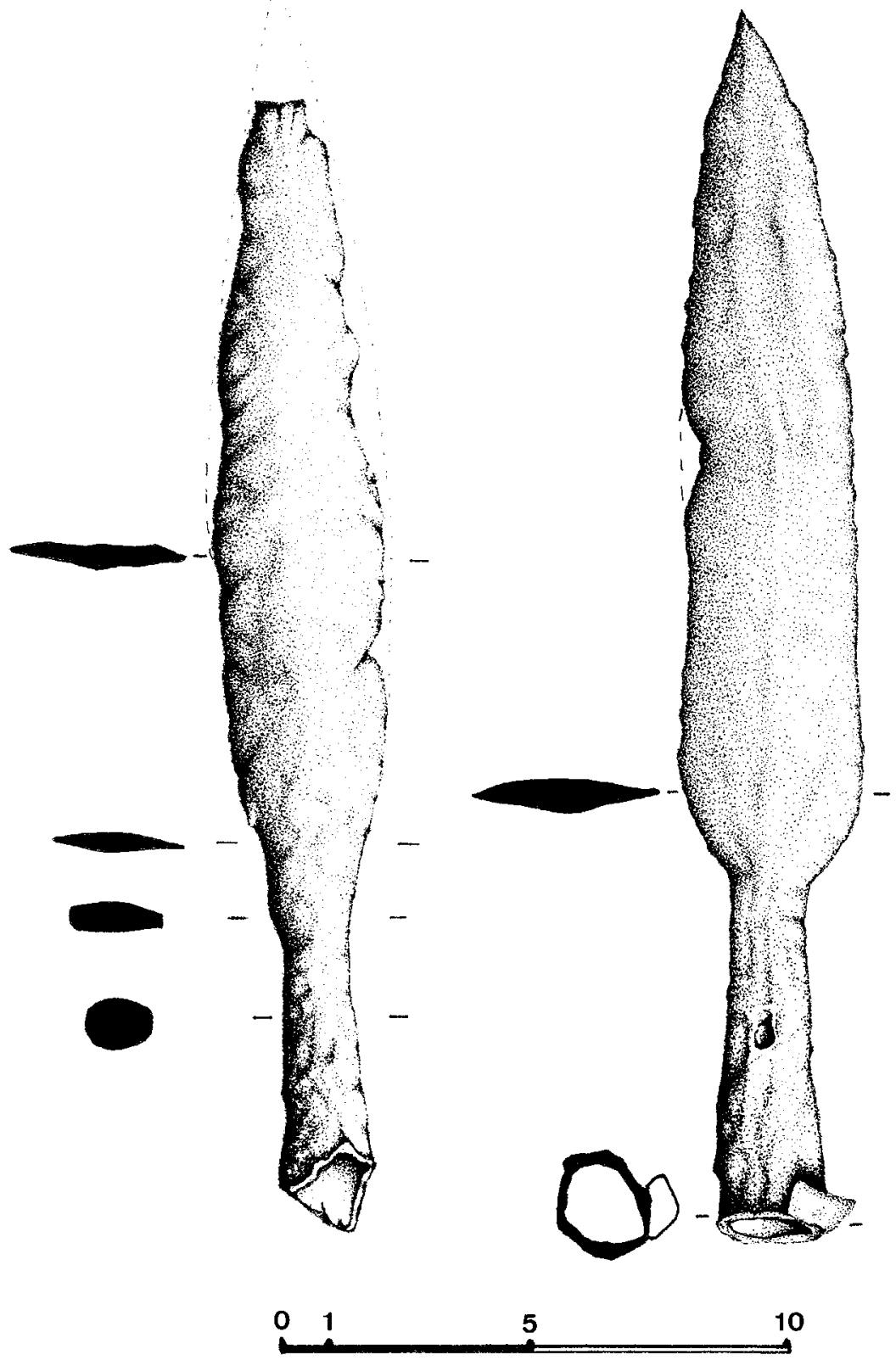

Fig. 9. Puntas de jabalina o de lanza de la Sepultura 13 del Cerro de Las Balas. 

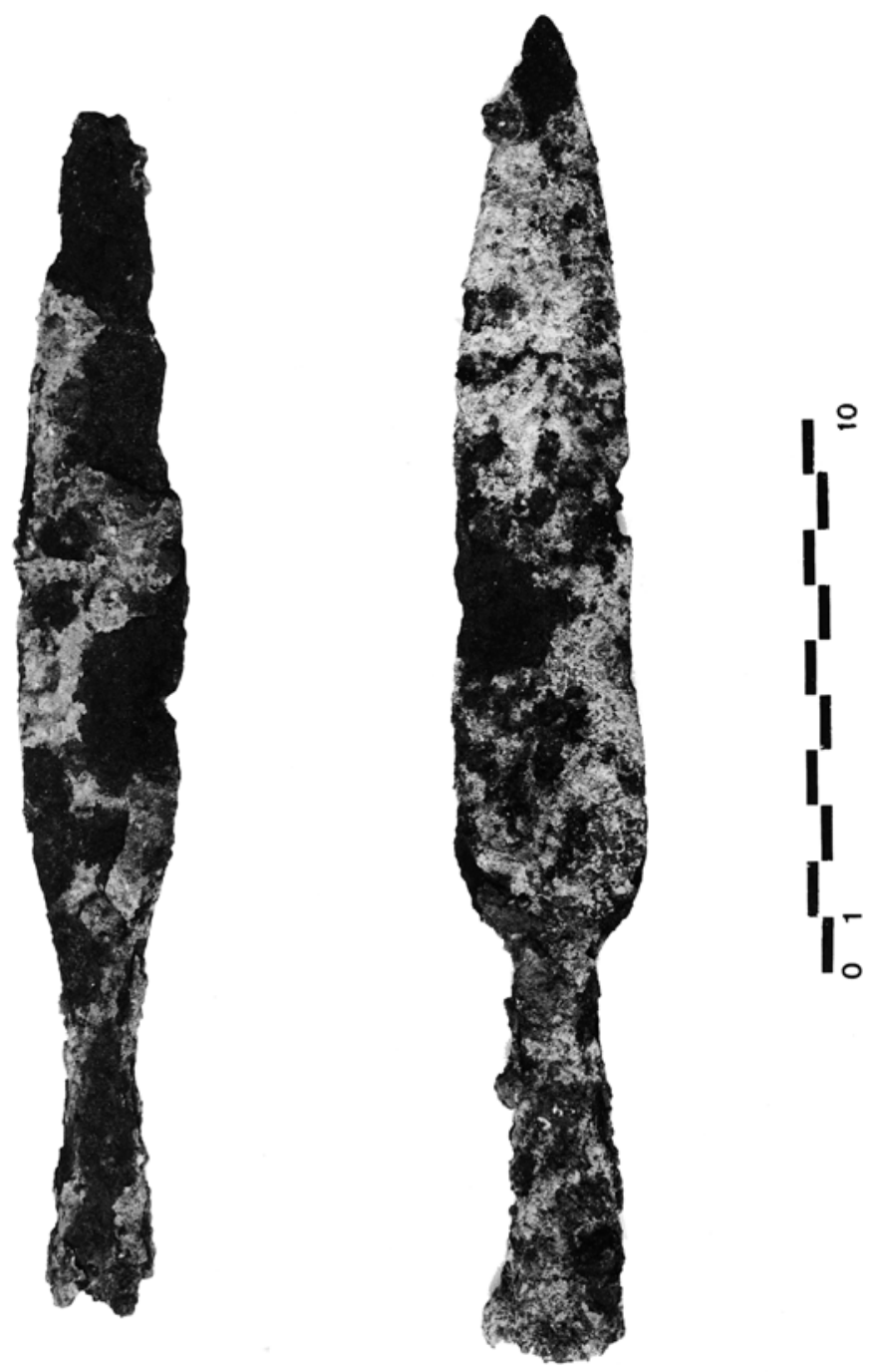

Lám. X. Puntas de lanza o jabalina.

Ambas variantes (VIIBa y VIIBb) fueron estudiadas juntas ${ }^{41}$. Son siempre armas cortas, de entre 20 y $30 \mathrm{~cm}$. de longitud máxima. Aunque hay piezas de este tipo en fechas antiguas (La Solivella) y de plena época Ibérica (La Bastida, Alcacer do Sal, Almedinilla), otras muy características coinciden plenamente en cronología tardía con las piezas que estudiamos, en especial las puntas del poblado del Cerro de la Cruz en Almedinilla (por citar un ejemplo andaluz) u otras de las necrópolis de Gormaz y Osma (por citar ejemplares meseteños). En la clasificación definitiva por tipos, los 8a y 9a están muy cercanos, agrupándose con las variantes VIICa y VIICb respectivamente, de aspecto más macizo por su menor relación longitud/anchura ${ }^{42}$. En realidad, se trata de tipos bastante elementales, poco llamativos formalmente, que corresponden a la idea genérica de 'lanza' susceptible de fácil y rápida fabrica-

41 Quesada (1997a:377 ss., especialmente Figura 226).

42 Ibidem Fig. 226 y Figuras 244-245. 
ción masiva para un periodo o una 'clientela' poco exigente, y que aparecen tanto en la Meseta como en el área propiamente ibérica.

La ausencia de regatones en la tumba, la falta de nervio en la hoja, el pequeño tamaño y similares características de las dos piezas nos hacen pensar que nos encontramos más bien ante dos jabalinas, armas de asta pensadas para su empleo como armas arrojadizas a distancia media-corta (entre 40 y 15 metros más o menos), pero susceptibles también de empleo empuñado, en especial la de filos más paralelos (Lámina X, derecha). Ambas piezas pueden también tener un uso como armas de caza que otras lanzas mucho mayores y de nervio acusado desempeñarían mal.

\section{VALORACIÓN (1). LA PANOPLIA. LA AUSENCIA DE ESCUDO.}

El conjunto de armas ofensivas depositadas en esta sepultura es característico de una panoplia ofensiva muy completa: dos armas de asta de empleo mixto pero fundamentalmente arrojadizas, una potente espada de uso doble, cortante y punzante, y completando el conjunto como arma más de prestigio que de combate, un puñal de empuñadura dobleglobular que, cuando el bronce brillara limpio, debía resultar muy llamativo. Es pues el conjunto de una tumba propia, no tanto de un jefe o persona de alto rango (la tumba no presenta ningún otro elemento destacado de estatus) sino, quizá, de un guerrero 'profesional' que porta una panoplia completa.

El único elemento discordante en el cuadro es la completa ausencia de armamento defensivo. Cabría en este contexto esperar la presencia de un casco de bronce de tipo Montefortino, aunque tal lujo no debía ser habitual para los guerreros ibéricos ni siquiera en el s. II a.C. ${ }^{43}$ Sin embargo, lo que parece más chocante es la ausencia de restos de escudo. Sin embargo, teniendo en cuenta lo que sabemos de los escudos en Baja Epoca Ibérica, lo que cabría esperar es, más que un escudo circular con la característica manilla de aletas típica de Plena Epoca Ibérica ${ }^{44}$, un escudo de tipo oval. Y precisamente los escudos ovales de tipo helenístico que se emplean en Iberia a partir de la II Guerra Púnica se caracterizan porque pueden llevar umbo metálico, como en los relieves de Osuna ${ }^{45}$, pero pueden no tener umbo alguno, como en la cerámica de Liria. En cuanto a la manilla de estos escudos, no tiene por qué ser metálica, sino de madera o incluso de tiras de cuero cruzadas ${ }^{46}$, con lo que el único resto metálico que quedaría sería unos clavos de hierro que pueden corroerse con facilidad. Por tanto, es posible que el ajuar de la tumba contara originalmente con un escudo oval, que no dejaría restos metálicos. Por fin, puede también que no se depositara armamento defensivo alguno.

\section{VALORACIÓN (2). TUMBAS CON ARMAS DE LA SEGUNDA EDAD DEL HIERRO EN ANDALUCÍA OCCIDENTAL.}

La aparición de una tumba con ajuar de armas en Andalucía Occidental es un hallazgo lo suficientemente raro y notable como para merecer una atención individualizada. En realidad, los hallazgos de armas de la Segunda Edad del Hierro en el territorio de las actuales provincias de Huelva, Sevilla y Cádiz es un acontecimiento excepcional, casi tanto como lo es la aparición de restos funerarios de esta época. No entraremos en la vieja discusión sobre la

\footnotetext{
43 Quesada (1997a:554 ss.) (1997d passim).

44 Quesada (1997a:497 ss. y Lám.XA).

45 Quesada (!997a: Lám. XIIIA).

46 Ibidem pág.955, ํㅡ. 44, vaso de Archena. Ver también págs. 535-547 y en particular, pág. 542.
} 
causa de la ausencia de necrópolis turdetanas fechables entre los siglos V-III a.C., y la extrema escasez de tumbas fechables entre los siglos III-I a.C., cuestión sobre la que hasta ahora no hay un consenso ${ }^{47}$. De lo que no cabe duda es de que la gran escasez de armas de estos periodos en Andalucía Occidental guarda una relación directa con este fenómeno, puesto que en Andalucía Oriental las numerosas armas conocidas proceden de contextos funerarios en la casi totalidad de los casos. Aceptado esto, procede examinar la naturaleza de los datos conocidos, para ver si es posible extraer de ellos algún patrón y tratar de insertar en él la tumba 13 del 'Cerro de las Balas'.

Partimos de la base de que la cuestión de la escasez de armamento de la Segunda Edad del Hierro en Andalucía Occidental no tiene necesariamente por qué estar relacionada con la escasez de armas en el Periodo Orientalizante en la misma región, aunque esa es una cuestión en la que no entraremos aquí ${ }^{48}$.

Los hallazgos de la Baja Andalucía, sueltos y a menudo descontextualizados, pueden agruparse así: dos espadas, una de antenas de tipo III de Quesada, hallada en el Caserón de Evorillas, cerca de Sanlucar de Barrameda, en Cádiz, y otra de pomo facetado de tipo IV de la necrópolis de Mesas de Asta, cerca de Jerez, en Cádiz, indican que las espadas de hoja recta y corta y pomo de antenas atrofiadas no estabn por completo ausentes en Andalucía Occidental durante el siglo IV a.C. ${ }^{49}$. Su tipología y fecha probable se alejan sin embargo de las armas del Cerro de las Balas.

La gran punta de lanza de la Rinconada (Cerro Macareno, Sevilla) y el soliferreum del Prado de San Sebastián (Sevilla) están mal documentados, su contexto es desconocido y su amplia cronología puede abarcar desde el s. IV a. I a.C. ${ }^{50}$.

Mucho más proximas, cronológica y culturalmente, están el casco sacado del Guadalquivir en las cercanías de San Juan de Aznalfarache (Sevilla), y la tumba con armas (incluyendo espada recta, lanza de tipo meseteño y umbo bivalvo de tipo laténico) hallada en la necrópolis de El Hinojal (Cádiz) ${ }^{51}$. Sin embargo, la tumba supuestamente tardía del Hinojal plantea serios problemas de cronología que requerirán un estudio más a fondo, y el casco del Guadalquivir no puede datarse con la precisión neccesaria, por lo que no podemos ponerlo en relación directa con el Cerro de las Balas.

Otro pequeño lote de armas de las cercanías de Marechena está actualmente en estudio ${ }^{52}$. Por fin, las armas de Osuna son ya de época cesariana y se salen del marco de nuestro estudio.

En conjunto, pues, comienzan a conocerse algunas armas interesantes en esta región, pero sus contextos son todavía demasiado dudosos, y sus zonas de aparición demasiado dispersas, como para poder hacer una ajustada valoración de conjunto.

$47 \mathrm{Al}$ respecto, y como muestra de las posturas encontradas, Escacena (1989) y Bendala (1992). Pero ver la noticia del descubrimiento de una probable gran necrópolis de la Edad del Hierro en Mesas de Asta (Cádiz) en González, Barrionuevo, Aguilar (1997), que pueda alterar los términos del debate..

48 Para esta cuestión, resumen y discusión en Quesada (1997a: 605-609).

49 Espada de Caserón de Evorillas: Quesada (1997a: 761, yacimiento no. 313; espada num. cat. 604, pág. 849). Espada de Mesas de Asta: Quesada (1997a: yacimiento no 455; espada num cat. 6209, pág. 852). Se indica la bibliografía anterior. Discusión sobre los tipos en páginas 206 ss.

50 Lanza de La Rinconada: Quesada (1997a: num. yac. 185, pág. 743; num. cat. 2079, pág. 877). Soliferreum del Prado de San Sebastián: Quesada (1997a: núm. yac. 183, pág. 743; núm. cat. 2077, pág. 868).

51 Casco de S. Juan de Aznalfarache: Quesada (1997a: yacim. n. 442, pág. 762; num. cat. 5888, pág., 934). Tumba de El Hinojal: Quesada (1997a: yacim. 182, pág. 743; armas nos. cat. 2155, 2156, 2158). Esta última tumba plantea problemas, porque el umbo de escudo bivalvo parece muy antiguo, del s. IV a.C. (Quesada, 1997a:540-541).

52 Agradecemos al Dr. Eduardo Ferrer Albelda que nos haya dado a conocer estas piezas. 
VALORACión (3). El 'CERRO DE LAS BALAS', LA TUMBA DE GUERRERO Y LA BATALla DE MUNDA. EN TORNO A LOS PELIGROS DE LA 'FALACIA POSITIVISTA'.

Analizar una tumba con armas de Baja Epoca Ibérica en una zona plagada además de glandes de honda de época romano-republicana muy tardía implica realizar, al menos, alguna referencia a la cuestión de la terrible batalla de $M u n d a$, librada en el año 45 a.C. entre un ejército pompeyano al mando de Gneo Pompeyo y Julio César (Bell. Hisp. especialmente 28 ss.).

Sobre la localización del campo de batalla de Munda se han propuesto varias soluciones, que pueden sintetizarse convenientemente del modo que sigue (Figura 1):

a. En Monda, al oeste de la moderna Málaga y ya cerca de la costa, idea hace tiempo desechada con plena justicia

b. En los Llanos de Vanda, pocos kilómetros al Norte de la actual Montilla, al Sur de Córdoba y al Este de Sevilla.Casi desechada por la investigación moderna.

C. En la zona del Cortijo de Alhonoz, junto a la margen izquierda del Genil, a menos de diez kilómetros al Este de la moderna Puente Genil.

c. En Lora de Estepa, a cinco kilómetros al Este-Sureste de Estepa. Desechada por la investigación.

d. Entre Osuna, la antigua Urso, y Ecija (Astigi) por tanto bastante más al oeste que en las propuestas anteriores. Diferentes variantes de esta teoría han tratado de precisar aún más. R. Corzo ubica Munda en el Cerro de la Atalaya, por tanto identificandola con el poblado al que corresponde la necrópolis que venimos estudiando (Figura 1) ${ }^{53}$. V. Durán y M. Ferrero ubicaron el campo de batalla en los Llanos del Aguila, unos cinco kilómetros en línea recta al sur del Cerro de la Atalaya, y al pie del Alto de las Camorras, donde habría estado el campamento pompeyano y la propia Munda ${ }^{54}$.

La verdad es que los hallazgos arqueológicos de la zona, en especial glandes de honda, y el notable botón de plata con el nombre A.VARO parecen una confirmación bastante satisfactoria de que la batalla se dió en esta zona al sur de Ecija y poco al norte de Osuna, y probablemente en los Llanos del Aguila.

Más difícil parece decidir si la Munda antigua debe buscarse en el Cerro del Aguila como propone R. Corzo (y en ese caso Carruca sería el Alto de las Camorras), o en el Alto de las Camorras como más recientemente quieren V. Durán y M. Ferreiro, con buen conocimiento del terreno y siguiendo a otros autores como F. Didierjean (y en ese caso Carruca estaría en el Cortijo de Cosmes) ${ }^{55}$. En el primer caso, la batalla se habría dado sobre la necrópolis que analizamos. El hallazgo de numerosos glandes con el epígrafe $\mathrm{CN}$ (eus) MAG(nvs) IMP(erator) en ambos yacimientos (cercanos entre sí, a menos de ocho kilómetros) no ayuda a fijar una decisión. Sin embargo, los argumentos sumados por Ferreiro parecen en conjunto los más convincentes ${ }^{56}$, pese a lo que no nos atrevemos a considerarlos definitivos.

Ahora bien, la inmediatez de este campo de batalla al cementerio que nos ocupa no debe impulsarnos a la falacia de tratar de asociar uno con otro. Ya hemos visto que, en principio, la creonología del conjunto de materiales apunta mejor a una datación en las primeras décadas del siglo II a.C. que a una de mediados del I a.C. Ahora bien, tipológicamente no es imposible, ni mucho menos, que los materiales metálicos pudieran llegar a esa cronología: simplemente, el estado actual de nuestros conocimientos no permite afinar más; la espada y el puñal podrían concebiblemente ser de época cesariana, aunque lo que por ahora sabemos nos

\footnotetext{
53 R. Corzo (1973).

54 V. Durán (1984); V. Durán, M. Ferreiro (1984); M. Ferreiro (1986-87).

55 R. Corzo (1973). V. Durán, M. Ferreiro (1984). M. Ferreiro (1986-87). F. Didierjean (1983).

56 Ferreiro (1986-87:128-129).
} 
hace dudarlo. La cerámica de barniz negro podría haber sido amortizada tardíamente (hay numerosos ejemplos de este tripo de suceso). Sin embargo, ya estaríamos forzando en exceso los datos. Finalmente, está la cuestión del contexto: en un campo de batalla lo esperable es encontrar fosas comunes, si acaso, y una solitaria tumba de guerrero, con urna y todo, dentro de un cementerio indígena con otras sepulturas similares pero sin armas, no parece adecuarse a las circunstancias posteriores a una grean batalla. No caigamos pues en la falacia: nada nos autoriza a relacionar esta tumba con la batalla de Munda, y sí muchos datos apuntan a un contexto puramente turdetano un siglo o siglo y medio anterior... lo que no impide que, quizá, este individuo en concreto hubiera servido en un ejército romano.

\section{VALORACIÓN (4). IBEROS Y ROMANOS. ARMAS IBERAS Y ARMAS ROMANAS. ARMAS IBERAS Y ARMAS CELTÍBERAS.}

$\mathrm{Si}$, como parece, el conjunto de la tumba 13 del Cerro de las Balas puede datarse en las primeras décadas del s. II a.C., se plantea a partir de la aparición del puñal y la espada la espinosa cuestión cultural. La tumba es incuestionablemente de carácter indígena, por el ambiente del cementerio, el ritual empleado, la urna cineraria, etc. En este contexto, lo más prudente es considerar las armas como propiedad de un guerrero turdetano o ibero, pero desde luego no un soldado romano o latino. Hasta aquí no hay problema. Las dificultades surgen cuando tratamos de definir, por ejemplo, el tipo de la espada: ¿indígena o romano? Porque, como se ha visto, los primeros gladii hispanienses debieron ser indistinguibles de las espadas ibéricas que copiaban, proceso que probablemente se produjo justo en la transición entre el s. III y el II a.C. Algo parecido puede decirse del puñal. Por el contexto, son armas indígenas, turdetanas o, si se quiere, iberas o celtíberas. Pero bien pudo ocurrir que el guerrero aquí sepultado combatiera en las filas del ejército romano, como uno de tantos auxiliares, mercenarios y aliados, que habían comenzado a reclutar primero los Escipiones y luego los siguientes generales romanos. En ese caso, la espada sería tanto ibérica como romana. En un último análisis, la cuestión es absurda y no tiene respuesta: en un momento de cambios intensos y profundas alteraciones en la esfera militar como en tantas otras, la cuestión de si la espada y el puñal pueden ser consideradas ibéricas o romanas es irresoluble. Estas piezas en concreto posiblemente debamos etiquetarlas como 'ibéricas' en sentido lato; pero estas mismas en un campamento numantino o algo anterior podrían perfectamente ser consideradas 'romanas'.

Desde otro punto de vista, cabe plantear que el conjunto de armas depositado en esta tumba — espada recta, puñal dobleglobular, lanzas cortas sin nervio- parece más apropiado a un contexto cultural meseteño o en todo caso extremeño, que al ámbito turdetano. Aquí nos encontramos en realidad ante un serio problema: la práctica ausencia de armas turdetanas nos impide saber cómo era su panoplia, y por tanto adscribir estas armas a un mercenario celtíbero porque en realidad no sabemos cómo eran las armas turdetanas es un contrasentido. Por otro lado, los datos iconográficos del monumento de Osuna, muy cerca del Cerro de las Balas (Figura 1), y datable probablemente en el s. II a.C. o poco antes, son perfectamente compatibles con las armas de esta tumba. Así, el guerrero del relieve conservado en Paris lleva escudo oval y al hombro una espada del tipo del gladius hispaniensis, y otro guerrero porta en otro relieve un puñal que podría bien ser del tipo dobleglobular. ${ }^{57}$ En realidad, en una época tan revuelta y confusa como el tránsito del s. III al II a.C., y durante toda esta centuria, con ejércitos subiendo y bajando por todas las rutas, con reclutas masivas de auxiliares y

57 Ver Quesada (1997a:242). Ilustraciones en último lugar en Rouillard (1997:30-33). Sobre la cronología, además de nuestro trabajo anterior, pág. 541, ver Leon Alonso (1981). 
mercenarios, las distinciones armamentísticas debieron hacerse mucho más tenues, y debió irse imponiendo una cierta homogeneidad 'a la romana' 58 .

\section{BIBLIOGRAFÍA}

ARIAS, G. (1987): Repertorio de caminos de la Hispania Romana. s/l.

Aubet Semmler, M:E. (1981): La necrópolis de Setefilla en Lora del Río (Sevilla). En Andalucía y Extremadura, I. Barcelona, págs. 53-229.

BENDAla GaláN, M. (1992): «La problemática de las necrópolis tartésicas». Congreso de Arqueología Ibérica: las necrópolis. Madrid, págs. 27-36.

BishoP, M.C.; COUlSton, J. (1993): Roman Military equipment from the Punic Wars to the fall of Rome. London.

CABRE DE MORÁN, E. (1990): «Espadas y puñales de las necrópolis celtibéricas». F. Burillo (ed.) II Simposio sobre los celtíberos. Necrópolis celtibéricas. Zaragoza, págs. 205-224.

CABRE DE MORÁN, E.; MORÁN CABRE, J.A. (1991): «Puñales dobleglobulares con probable simbología astral en el pomo de la empuñadura». XX Congreso Nacional de Arqueología. Zaragoza, págs. 341-348.

Caruz Arenas, A. (1978): «La última campaña de César en la Bética: Munda». Primer Congreso de Historia de Andalucía. Córdoba, págs. 143-155.

Connolly, P. (1997): «Pilum, Gladius and Pugio in the Late Republic». En M. Feugère (ed.) L'équipement militaire et l'armement de la République, en Journal of Roman Military Equipment Studies 8, págs. 41-57.

CORZO SÁnCHEZ, R. (1973): «Munda y las vías de comunicación en el Bellum Hispaniense». Habis 4, págs. 241-252.

CORZO SÁNCHEZ, R. (1992): Las vías romanas de Andalucía. Sevilla.

DICOCER (1993): Dictionnaire des Céramiques antiques en Méditerranée nord-occidentale. Lattara 6. Lattes.

DIDIERJEAN, F. (1983): «Enceintes urbanes antiques dans la province de Seville». Prospections aériennes. Les paysages et leur histoires. Cinq campagnes de la Casa de Velázquez. París.

Durán ReCio, V.; Ferreiro LóPez, M. (1984): «Acerca del lugar donde se dio la batalla de Munda». Habis 15, págs. 229-235.

Durán Recio, V.; Padilla Monge, A. (1990): Evolución del poblamiento antiguo en el término municipal de Ecija. Ecija.

EsCACENA CARRASCO, J.L. (1986): Cerámicas a torno pintadas andaluzas de la Segunda Edad del Hierro. Tesis Doctoral Universidad de Sevilla.

ESCACENA CARRASCO, J.M. (1989): «Los turdetanos o la recuperación de la identidad perdida». Tartessos. Arqueología protohistórica del Bajo Guadalquivir Sabadell, págs. 433-476.

FERREIRO LÓPEZ, M. (1986-87): «Munda y el campus mundensis». Anales de la Universidad de Cádiz, 3-4, págs. 123-135.

FERreiro LóPez, M. (1988): César en España. Cádiz.

Ferreiro LóPEZ, M. (1994): «Cronología de la campaña de Munda». Homenaje al Profesor Presedo. Sevilla, págs. 435-450.

FeUGERE, M. (1994): «L'équipement militaire d'epoque republicaine en Gaule».Journal of Roman Military Equipment Studies 5, págs. 3-23.

\footnotetext{
58 Sobre el tema, Quesada (1997a: 544 ss. y sobre todo 659-663.
} 
Filloy Nieto, I.; Gil Zubillaga, E. (1997): «Las armas de las necrópolis celtibérica sde Carasta y La Hoya (Alava, España). Tipología de sus puñales y prototipos del pugio». En M. Feugère (ed.) L'équipement militaire et l'armement de la République, en Journal of Roman Military Equipment Studies 8, págs. 137-150.

GonZÁlez RodríGuez, R.; BARrionuevo Contreras, F.; Aguilar Moya, L. (1997): «Notas obre el mundo funerario en la Baja Andalucía durante el periodo turdetano». Actas de las Jornadas La Andalucia Ibero-Turdetana (siglos VI-IV a.C.), Huelva,1994. Huelva Arqueológica 14, págs. 247-268.

Hernandez Díaz, J.; SANCho Gorbacho, A.; Collantes de Teran, F. (1951): Catálogo arqueológico y artístico de Sevilla y su provincia. T. III. Ecija. Sevilla.

Horvat, J. (1997): «Roman Republican weapons from Smihel in Slovenia». En M. Feugère (ed.) L'équipement militaire et l'armement de la République, en Journal of Roman Military Equipment Studies 8, págs. 105-120.

IrIarte, A.; García, M.L.; Filloy, I. Gil, E.; SeSma, J. (1996): «El depósito de armas de La Azucarera (Alfaro, la Rioja). Cuadernos de Arqueología de la Universidad de Navarra, 4, págs. 173-194.

IrIARTE, A.; GiL, E.; Filloy, I.; GarCía, M.L. (1997): «A votive deposit of Republican weapons at Gracurris (Alfaro, La Rioja, Spain)». En M. Feugère (ed.) L'équipement militaire et l'armement de la République, en Journal of Roman Military Equipment Studies 8, págs. 233-250.

Lamboglia, N. (1952): «Per una classificazione preliminare della ceramica campana». Atti I Congresso Ionternazionale di Studi Liguri, Bordighera, págs. 139-206.

LeÓn Alonso, P. (1981): «Plástica ibérica e iberorromana». La Baja Epoca de la Cultura Ibérica. Madrid, págs. 183-199.

LóPez PALOMO, L.A. (1999): El poblamiento protohistórico en el valle medio del Genil. Ecija.

LuZÓN, J.M. (1973): Excavaciones en itálica. Estratigrafía en el Pajar de Artillo (campaña de 1970). Excavaciones Arqueológicas en España 78. Madrid.

MelChOR GIL, E. (1995): Vías romanas de la provincia de Córdoba. Córdoba.

Morel, J.P. (1981): Céramique campanienne: les formes. I-II. Rome.

NúÑEZ PARIENTE De LeON, E.; MúÑOZ Tinoco, J. (1988): «Excavación en la necrópolis del Cerro de las Balas. Ecija. Sevilla». Anuario Arqueológico de Andalucía. 1988, vol. III, págs. 429-433.

PEREIRA Sieso, J. (1988): La cerámica pintada a torno en Andalucía entre los siglos VI y III a.d.C. Cuenca del Guadalquivir. Tesis Doctoral U.C.M. Madrid.

QUESADA SANZ, F. (1997a): El armamento ibérico. Estudio tipológico, geográfico, funcional, social y simbólico de las armas en la Cultura Ibérica. Monographies Instrumentum 3. Montagnac.

QUESADA SANZ, F. (1997b): «Gladius hispaniensis: an archaeological view from Iberia». En M. Feugère (ed.) L'équipement militaire et l'armement de la République, en Journal of Roman Military Equipment Studies 8, págs. 251-270.

QUESADA SANZ, F. (1997c): «¿Qué hay en un nombre?. La cuestión del gladius hispaniensis». Boletín de la Asociación Española de Amigos de la Arqueología 37, págs. 41-58.

QUESADA SANZ, F. (1997d): «Montefortino-type and related helmets in the Iberian peninsula: a study in archaeological context». En M. Feugère (ed.) L'équipement militaire et l'armement de la République, en Journal of Roman Military Equipment Studies 8, págs. 151-166.

QuesadA SANZ, F. (2000): «Puñal legionario». La Aventura de la Historia 15, págs. 100-101.

ROLDÁN HERVÁs, J.M. (1973): Itineraria Hispana. Granada.

Rouillard, P. (1997): Antiquités de l'Espagne. Paris.

SANMARTI GREGO, E. (1978): La cerámica campaniense de Emporion y Rhode. I-II. Barcelona.

SANMARTI GREGO, E.; PRINCIPAL, J. (1997): «Las cerámicas de importación, itálicas e ibéricas, procedentes de los campamentos numantinos». Revista d'Arqueología de Ponent 7, págs. 35-75.

UlBERT, G. (1984): Caceres el Viejo. Ein spätrepublikanisches legionslager in Spanisch-Extremadura. Madrider Beiträge 11. Mainz. 
VAQuerizo, D.; QueSADA; F.; MuRILlo, J.F. (1992): «La cerámica ibérica del 'Cerro de la Cruz' (Almedinilla, Córdoba). Departamentos O,P, Ñ». Anales de Arqueología Cordobesa 3, págs. 51-112.

Ventura MartíneZ, J.J. (1985): «La cerámica campaniense de la 'Cuesta del Rosario' (Sevi1la)». Archivo Español de Arqueología 58, págs. 41-68.

\section{FERNANDO QUESADA SANZ}

Dpto. De Prehistoria y Arqueología, Facultad de Filosofía y Letras

Universidad Autónoma de Madrid, 28049 MADRID

fernando.quesada@uam.es

ESTHER NÚÑEZ PARIENTE DE LEÓN

Servició de Investigcaión

Consejería de Cultura, Junta de Andalucía

c./Levies, 27. 41004 SEVILLA

bester@wanadoo.es 